Portland State University

PDXScholar

Summer 9-1-2017

\title{
Identifying Clusters of Non-Farm Activity within Exclusive Farm Use Zones in the Northern Willamette Valley
}

Nicholas Chun

Portland State University

Follow this and additional works at: https://pdxscholar.library.pdx.edu/open_access_etds

Part of the Agriculture Commons, and the Urban Studies Commons Let us know how access to this document benefits you.

Recommended Citation

Chun, Nicholas, "Identifying Clusters of Non-Farm Activity within Exclusive Farm Use Zones in the Northern Willamette Valley" (2017). Dissertations and Theses. Paper 3888.

https://doi.org/10.15760/etd.5776

This Thesis is brought to you for free and open access. It has been accepted for inclusion in Dissertations and Theses by an authorized administrator of PDXScholar. Please contact us if we can make this document more accessible: pdxscholar@pdx.edu. 


\title{
Identifying Clusters of Non-Farm Activity
}

within Exclusive Farm Use Zones in the Northern Willamette Valley

\section{by}

\section{Nicholas Chun}

A thesis submitted in partial fulfillment of the requirements for the degree of

\author{
Master of Urban Studies
}

Thesis Committee:

Megan Horst, Chair

Nathan McClintock

David Banis

Portland State University 
(C) 2017 Nicholas Chun 


\begin{abstract}
This thesis provides an extensive look at where permitted non-farm uses and dwellings have clustered within Exclusive Farm Use (EFU) zones in the Northern Willamette Valley in Oregon. There is a looming concern that non-farm related uses and dwellings, or non-farm development, are conflicting with agricultural preservation strategies. Specifically, non-farm developments can potentially undermine the critical mass of farmland needed to keep the agricultural economy sustainable, but until now, studies have lacked spatially precise data to systematically track these phenomena. This thesis offers methodological contributions towards analyzing these operations and presents a broad account of what has been occurring in the region. Using permit approval data from the Department of Land Conservation and Development (DLCD) and 2015 county tax lot shapefiles, I geocoded the locations of these uses and dwellings. I used location quotient and spatial autocorrelation coefficients to identify non-farm hotspots in the region and summarized different typologies that have developed. The findings reveal that viticulture operations have amassed near Dundee and Newberg in Yamhill County, while commercial activities and home occupations have clustered near the Salem-Keizer UGB. Concurrently, dwellings have clustered near the Yamhill-Polk County border. Finally, I offer suggestions to improve Oregon’s agricultural land use policy and data management process, as well as advocate for more intensive research in the future to generate narratives for our results.
\end{abstract}




\section{Acknowledgements}

I would like to thank my advisor and committee chair, Megan Horst, for guiding me throughout the thesis process and providing constructive feedback. I would also like to thank committee members Nathan McClintock and David Banis for their suggestions and comments. I would like to thank Charles Rynerson, Jason Jurjevich, Randy Morris, Kevin Rancik, and Uma Krishnan for their enduring support and wisdom. I am also grateful to Chris de Venecia, Jamaal Green, Steven Howland, and my five college brothers for their continued advice and friendship. I'd like to thank my parents and family, including the Gustavs, for their support and patience. To friends, colleagues, and professors I've unintentionally omitted, I am grateful for and humbled by the support and knowledge you have given me to make this possible. 


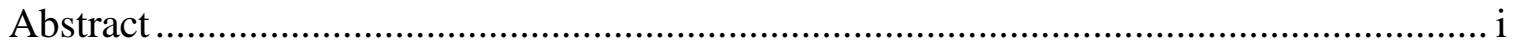

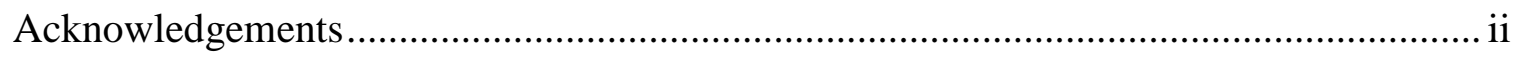

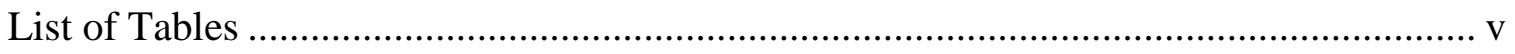

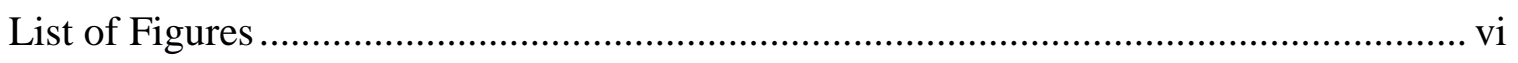

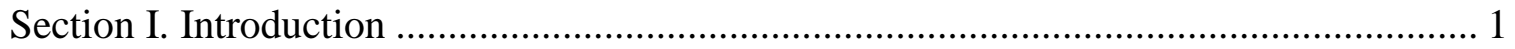

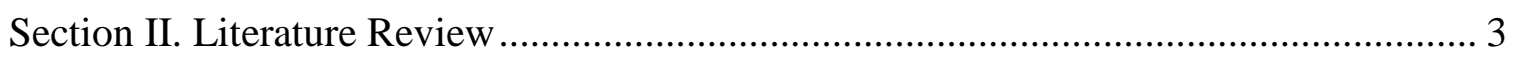

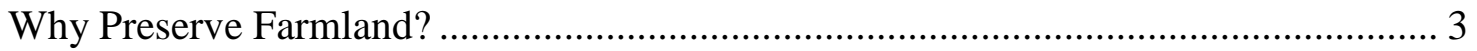

Preservation strategies for Oregon ....................................................................... 4

The Neoliberal Food System Model ......................................................................... 5

The Agrarian Question ........................................................................................ 5

Direct and Indirect Effects of Non-farm Activity …............................................. 7

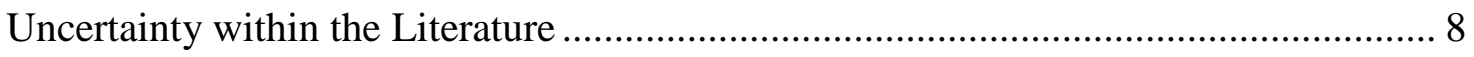

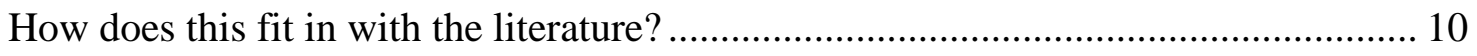

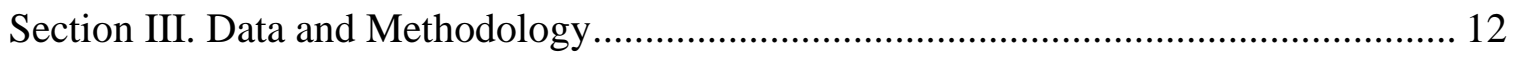

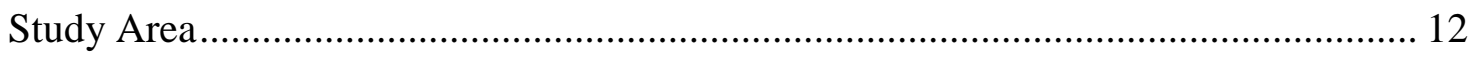

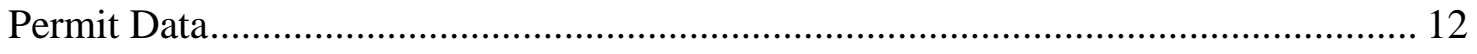

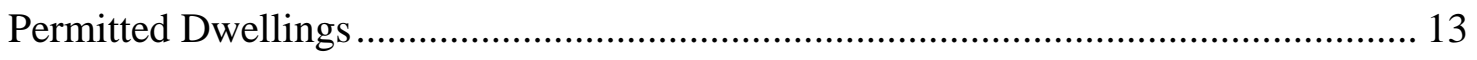

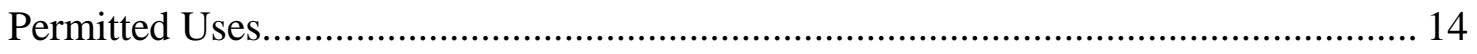

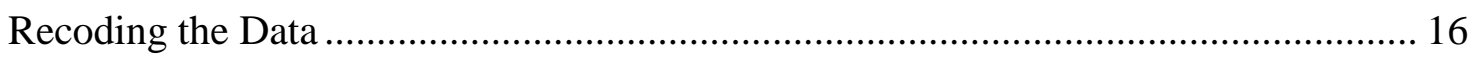

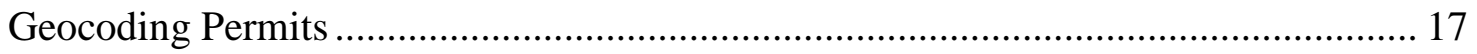

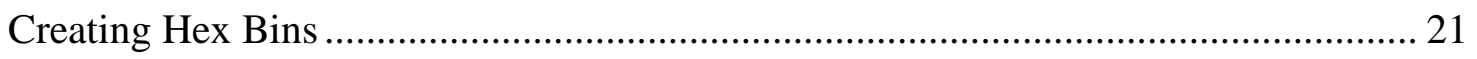

Location Quotient \& Spatial Autocorrelation (Anselin LISA) ................................. 23

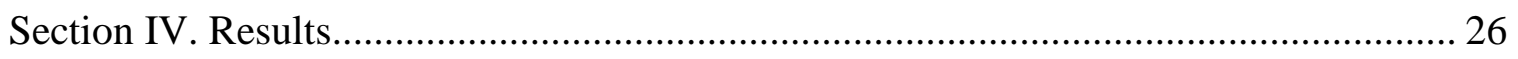

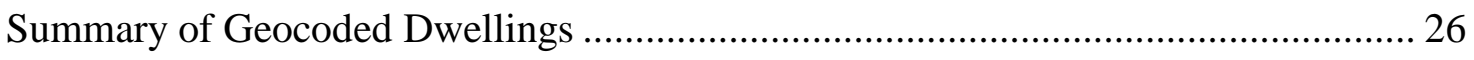

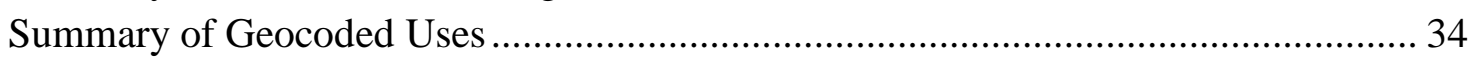

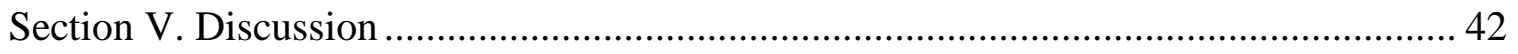

Section VI. Limitations and Future Research............................................................. 44

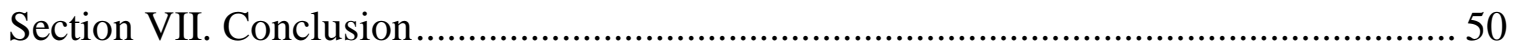




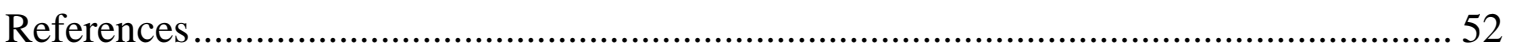

Appendix A: Additional Tables ............................................................................. 58

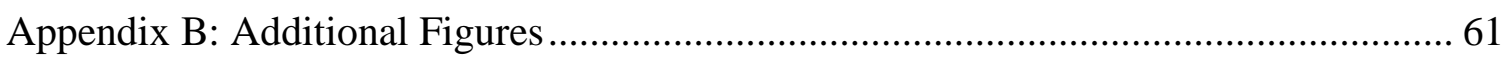

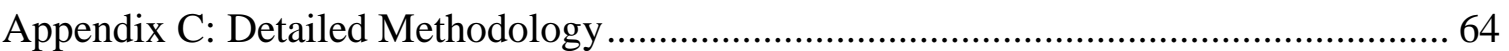




\section{List of Tables}

Table 1: Non-farm Use Subcategories .................................................................... 15

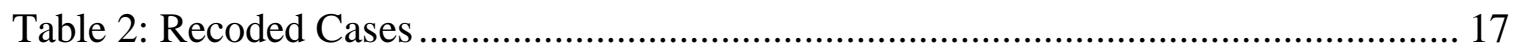

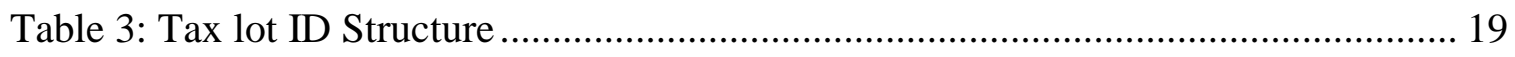

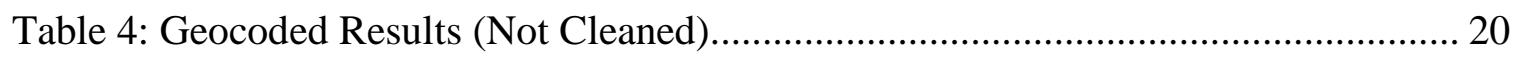

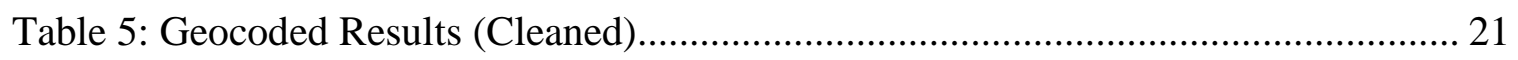

Table 6: Times Series Summary of Geocoded Dwellings ........................................... 26

Table 7: Summary of Geocoded Dwellings by County (Distinct \& Non-Farm) ............. 28

Table 8: Summary of Dwelling Hotspots (Distinct \& Non-Farm) ................................ 33

Table 9: Time Series Summary of Geocoded Uses ................................................... 35

Table 10: Summary of Geocoded Uses (Distinct \& Non-Farm) ................................... 36

Table 11: Summary of Use Hotspots (Distinct \& Non-Farm) ..................................... 40

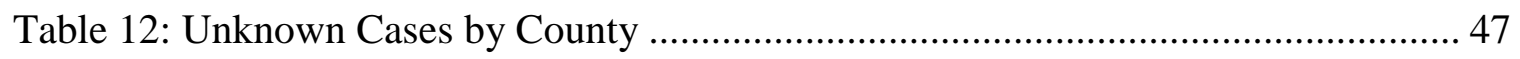

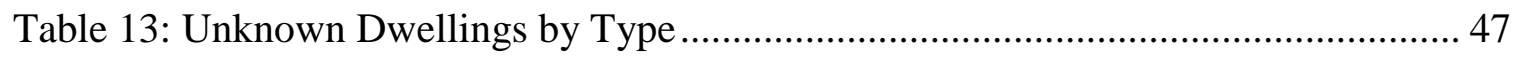

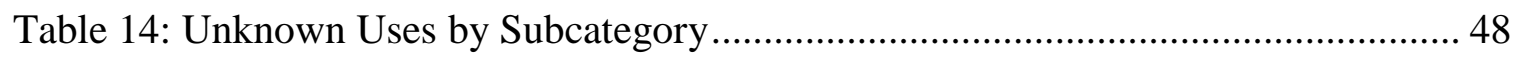


Figure 1: PLSS \& Tax lot Shapefiles......................................................................... 18

Figure 2: Hexagonal Grid (Study Area)..................................................................... 22

Figure 3: Location Quotient....................................................................................... 23

Figure 4: Hotspots \& Neighboring Areal Units .............................................................. 24

Figure 5: Geocoded Dwellings (Distinct \& Non-Farm) …………………………........... 28

Figure 6: Location Quotients for Geocoded Dwellings (Distinct \& Non-Farm)............... 30

Figure 7: Hotspots for Geocoded Dwellings (Distinct \& Non-Farm) ............................... 30

Figure 8: Geocoded Uses (Distinct \& Non-Farm) ........................................................... 37

Figure 9: Location Quotients for Geocoded Uses (Distinct \& Non-Farm) ........................ 38

Figure 10: Hotspots for Geocoded Uses (Distinct \& Non-Farm) ...................................... 39

Figure 11: Hotspots for Geocoded Non-Farm Uses ........................................................ 41 


\section{Section I. Introduction}

Oregon's land use policy plan has been lauded nationally as one of the most successful conservation strategies for agricultural and forest lands (Kline, 2005; Nelson, 1992; Tulloch, Myers, Hasse, Parks, \& Lathrop, 2003). Exclusive use zoning, such as urban growth boundaries (UGB) and exclusive farm use zones (EFU), separate activities with the intention to reduce conflicts that may occur between agricultural, urban, and rural communities. While Oregon's land use policies have been relatively successful in this regard, there is a concern that the growing number of permitted non-farm uses and dwellings within EFU zones may be undermining farmland conservation efforts (DLCD, 2017; Lehman, 2015). These activities are not homogenous, however, and there is difficulty in delineating the impacts of various operations. Golf courses, residential homes, and mining operations are a few operations not related to agriculture, but nonetheless exist within these zones. At the same time, other uses, such as processing facilities, farm worker residences, and storage facilities, play vital roles in maintaining farming practices. Agri-tourism and commercial activities are growing operations in many farms, though their effects may only be optimal to a point. While they provide additional income for businesses and further awareness of our local food system, an excess can create ripple effects that undermine the industry's ability to sustainably produce itself (DLCD, 2012, 2017; Lehman, 2015). Pluriactivity, or the co-existence of non-farm and farm operations (Brookfield, 2008; Busby \& Rendle, 2000; Fuller, 1990), has the potential to be a boon or a bane to Oregon's farmland, but the extent of this activity or where they are occurring has not been thoroughly measured. 
This study provides an extensive look at permitted non-farm uses and dwellings that have developed in the Northern Willamette Valley from 1993 to 2015. My research question is a simple, but important one: if and where has non-farm activity clustered in exclusive farm use zones in the Northern Willamette Valley? This study is an exploratory analysis, but due to data quality issues, I did not measure the impact of nonfarm activity on farming practices. Instead, the study's findings are intended to be a guide for researchers and policy makers interested in more intensive-laden research.

I start by framing the rise of non-farm activity within the larger context of the global food system. Next, I present dominant narratives from the discourse that explain the direct and indirect effects of non-farm activity on nearby farm operations. I complicate the conversation by highlighting uncertainties within the literature and methodological challenges studies have faced attempting to measure this phenomena. Using permit approval data from DLCD, I map out non-farm uses and dwelling permits that have existed on EFU land and identify statistically significant hotspots based on location quotient and spatial autocorrelation coefficients. I provide descriptive statistics of the clusters and summarize interesting trends in the data, as well as its limitations. Finally, I offer suggestions to how the data could be collected and managed more effectively. 


\section{Section II. Literature Review}

\section{Why Preserve Farmland?}

There has been increasing attention given to the future of farmlands vis-a-vis the growth of non-farm forms of production. Patterns of farmland loss that have coincided with the rise of the global food system and non-farm development have sparked interest within academia and governments to understand and curb this process (Condon, Mullinix, Fallick, \& Harcourt, 2010; Searle, 2012). Despite these trends, there are a variety of reasons why domestic farmlands should be preserved. Though farmlands near urban areas only make up a small percentage of the overall stock, most of the prime farmland, that is land that has the greatest potential for agricultural production, is located near urban areas where contention between non-farm and agricultural uses of land is highest (Berry \& Plaut, 1978; Nelson, 1992). While farmlands can be converted for nonfarm use, it is unlikely they will be converted back for agricultural production of similar quality (Berry \& Plaut, 1978; Bryant \& Russwurm, 1979; Nelson, 1992; Searle, 2012). Preserving farmlands can also reduce a region’s dependency and vulnerability to changes in the global food system (Bryant \& Russwurm, 1979; Condon et al., 2010). If managed properly, farmlands can also provide certain public goods, such as flood absorption, air cleansing and water filtration, as well as preserve open space and natural amenities (Nelson, 1992; Rose, 1984). The various positive externalities and long term sustainable production of agricultural land, assuming it is managed well, make it an important asset to maintain (Searle 2012). 


\section{Preservation strategies for Oregon}

Oregon remains one of the nation's most agriculturally productive state in large part to its land use program that attempts to regulates urban sprawl through UGBs (urban growth boundaries) and protect prime farmland (Kline, 2005; Lehman, 2015; Nelson, 1992). Specifically, Oregon's farmland conservation policies coincide with its statewide planning goal 3 to identify agricultural lands and maintain exclusive farm use (EFU) zones that encourage farming practices, protected from urban and rural conversion (DLCD, 2010, 2017). The success of the land use program, which demarcates urban, rural, and agricultural uses through exclusive zoning practices, should not be understated as farmland conversion rates in Oregon have slowed relative to other parts of the country including its neighbor, the state of Washington (DLCD, 2017; Kline, 2005; Nelson, 1992). At the same time, however, we must remain critical in the ways it has been limited. Contradictorily, a number of non-farm uses are permittable within exclusive farm use zones. According to ORS 215.213 and 215.262, the belief is that other uses and dwellings could co-exist with farm-related operations if they were placed on less productive farm land and did not negatively impact agricultural practices (DLCD, 2010;

Oregon Revised Statutes, 2015a, sec. 215.262, 2015b, sec. 215.213). An ongoing concern within the Department of Land Conservation and Development (DCLD) is the proliferation of permitted non-farm uses and non-farm dwellings within EFU zones. For the former, the number of allowed non-farm uses have increased from six back in 1963 to over fifty uses today (DLCD, 2017). The chronic rise of alternative forms of production is not occurring in a vacuum however, but partly as a response to growing contention between the agriculture industry within the global capitalist structure. 


\section{The Neoliberal Food System Model}

Growing economic burdens of farming is one reason to explain the rise of nonfarm development. Over the last 40 years, the neoliberalization of our food system, that is the unfettered privatization and corporatization of the agricultural industry at the expense of social welfare, has given agribusinesses hegemonic control over the production, distribution, and retail sectors of the food industry (Hendrickson, Heffernan, Howard, \& Heffernan, 2001; Howard, 2016; McMichael, 2009, 2013). More specifically, state subsidies for corporations, the elimination of minimum price thresholds for crops, and loose labor regulations in the global south have put a greater strain on farm producers to remain competitive (Ayazi \& Elsadig, 2015; McMichael, 2009, 2013). In reaction to these mounting pressures, farms must find ways to adapt to keep their operations economically sustainable in lieu of being squeezed out or consolidated (Friedmann, 1982; Lang, 2003; McMichael, 2009). This raises the question: how do farms stay competitive in an increasingly deregulated and unilateral market? For this, I turn to the "Agrarian Question.”

\section{The Agrarian Question}

The “Agrarian Question” is an ongoing discussion amongst rural sociologists and political economists surrounding the agricultural sector's resistance to capital consolidation (Kautsky, 1988; Mann \& Dickinson, 1978). While there are many facets to the discourse, the question of interest for this study is: how are farms able to resist being forced out of competition? Kautsky and Chayanov argue that small scale producers are driven by lifestyle choices rather than capitalist motivations for profit and consequently 
exploit themselves to maintain their autonomy (Kautsky, 1988; Mann, 1990). Mann and Dickinson add that natural barriers to farming, such as the immovability of the land, lengthy production times, and infrequent opportunities to realize capital gains, make the agricultural industry difficult to consolidate (Mann, 1990; Mann \& Dickinson, 1978). While the rapid expansion of our global food system has accelerated capital conquest in ways Mann and Dickinson did not foresee, farms are adopting alternative forms of production, or non-farm work, to increase their incomes and stay competitive. Income diversification, otherwise known as "pluriactivity," has been an important factor for farms’ ability to subsidize their operations (Brookfield, 2008; Busby \& Rendle, 2000; Fuller, 1990; Haugen \& Vik, 2008), but this diversification in turn may generate other non-farm activities less conducive to farming practices. I am not arguing against individuals seeking gainful opportunities, but the "push" away from farming as a viable mode of economic production and "pull" of alternative non-farm production place the long term outlook of Oregon's farmland in a precarious state. If left unaddressed, the implications of this trend go beyond lax regulations of land use laws, but may eventually undermine the effectiveness of Oregon's exclusive zoning policies as a whole. While EFU zones have largely protected farmlands from the direct effects of urbanization and non-farm uses, such as the conversion of farm land to different uses, the indirect effects from nearby non-farm activities on neighboring farms are less well known (Berry \& Plaut, 1978; Lockeretz, Freedgood, \& Coon, 1987; Nelson, 1992; Zollinger \& Krannich, 2002). 


\section{Direct and Indirect Effects of Non-farm Activity}

Many studies have discussed and debated the role of direct and indirect effects of non-farm activity on nearby farms. Direct effects are based on contentions between shortterm versus long-term values of farm land (Adelaja, Sullivan, \& Hailu, 2011; Berry \& Plaut, 1978; Nelson, 1992). Sprawl and/or increased population density from nearby areas can overvalue the development potential of farmland (short term) over the long term agricultural production (Wu, Fisher, \& Pascual, 2011; Zollinger \& Krannich, 2002). This overvaluation of greater immediate value and devaluation of lower long-term value is translated into policies and practices that convert prime agricultural lands for urban/non-farm use. Though Oregon has regulated this process by delegating most nonfarm uses and dwellings to less productive land (DLCD, 2017), there are a variety of indirect effects that may occur between neighboring farm and non-farm operations.

Most indirect effects discussed within the literature fall under two themes, both of which occur at spatially precise scales: "shadow effects" and the impermanence syndrome. Shadow effects refer to the negative externalities that occur when farming and non-farm activities are nearby one another. Some of the effects are as follows: (1) noise and pollution from farming techniques and machines can be nuisances to nearby residents and prompt complaints or disagreements, (2) increased services and infrastructures that accompany greater population density can disproportionately tax farmers, (3) pollution to crops from neighboring non-farm activity and traffic, (4) and harassment from neighbors (Berry \& Plaut, 1978; Bryant \& Russwurm, 1979; Nelson, 1992). These conflicts can create feelings of uncertainty amongst farm owners regarding the future of their 
operations if they perceive change occurring in neighboring areas (Adelaja et al., 2011; Berry \& Plaut, 1978; Zollinger \& Krannich, 2002). This is otherwise known as the impermanence syndrome, a self-fulfilling prophecy in which discouraged farm owners invest less resources or sell their land because they believe nearby non-farm developments will compromise the future of their farm operation (Lockeretz et al., 1987; Nelson, 1992; Wu et al., 2011).

\section{Uncertainty within the Literature}

Isolated non-farm operations are fairly harmless, but enough of them clustered together may threaten the "critical mass" of farmland, meaning the minimum supply of land needed for farming production to be sustainable (Nelson, 1992; Zollinger \& Krannich, 2002). The belief is if the supply of farmland drops below critical mass, farmland disinvestment and conversion will catalyze beyond the point of recovery (Adelaja et al., 2011; Berry \& Plaut, 1978; Kline, 2005; Nelson, 1992; Tulloch et al., 2003; Wu et al., 2011). Beyond theoretical discussions, however, our understanding of farmlands' critical mass remains fairly elusive. Lack of data and resources are the main reason research has been unable to determine what the minimum supply of farmland is, while others doubt that a uniform threshold even exists (Lynch, 2006; Lynch \& Carpenter, 2003; Tulloch et al., 2003; Wu et al., 2011). There are also conflicting narratives regarding the impacts of certain non-farm uses (DLCD, 2017; Lehman, 2015).

The "Farm \& Forest Report" released by DLCD every two years highlights housing and development trends in Oregon's farm and forest land (DLCD, 2017). Growth in agri-tourism, or agriculturally related and/or supportive events that attract visitors, 
wineries, and utility and energy facilities are a few trends DLCD has raised concerns about. Increasing awareness for Oregon's local food system has been a boon for viticulture and agri-tourism industries, which have simultaneously strengthened the consumer-producer relationship and have provided additional income for farms (DLCD, 2012, 2017; Lehman, 2015). While beneficial to individual businesses, the cumulative effects and residential traffic that accompany these growing industries may be detrimental to other farm operations that have not adopted such practices (DLCD, 2017; Lehman, 2015). Relatedly, investments in alternative energy sources have translated to a rise in the number of utility and energy facilities in EFU zones, which provide open space for facilities like wind turbines and solar panels to operate. Though their impacts appear to be relatively benign, the rise in transmission line corridors and other energy-related infrastructure has placed a growing onus for DLCD to monitor these activities (DLCD, 2017).

To reiterate, I am not against development or renewable energy, nor am I arguing with certainty that non-farm activity produces a net-negative impact on farmland preservation. While concerns presented in this section are appropriately addressed, I've identified a broader issue impacting Oregon's planning praxis. The problem I see is that non-farm uses and dwellings, inside protected agricultural zones, are proliferating unbeknownst to the majority of the public, while their impact on an increasingly precarious industry are nebulous. Uncertainties regarding the validity of the literature's dominant narratives and explanations go beyond epistemological fissures in the discourse. Fundamentally, past research has left more questions than it has answered for one principal reason: the lack of data at the appropriate geographic scale. 


\section{How does this fit in with the literature?}

Though some studies have tested the relationship between non-farm development and farmland conversion, data availability and quality have largely limited the effectiveness of their analyses (Kline \& Alig, 1999; Tulloch et al., 2003; Wu et al., 2011). In particular, there are issues of scale in quantitative studies using county level data to explain spatially precise interactions between farm and non-farm activity (Kline, 2005; Nelson, 1992; Wu et al., 2011). A relevant, but not wholly related, study that illustrates this ecological fallacy was conducted by Wu, Fisher, and Pascual (2011) to test the impacts of urbanization on nearby farmlands. They concluded that urbanization had an overall positive effect for nearby farms based on county-level data measuring net farm income per acre. Our response to their analysis is that changes in average farm income at the county level do not mean that farms benefited equally at sub-county levels. In other words, it is possible, if not probable, that increase in average income at the county level occurred through consolidation, meaning wealth accumulated for some farms at the expense of others. The illogical bridge using county level trends to explain parcel level phenomena is a product of poor data quality, something that has hindered researchers’ ability to properly analyze, let alone track, non-farm activity.

The purpose of our study is to provide an extensive look at non-farm uses and dwellings that have developed within EFU zones in the Northern Willamette Valley of Oregon using parcel level permit data. I realize that the data don't illustrate the full scope of non-farm activity that has occurred and, subsequently, recognize what they can and can’t say. Before future research can produce any defensible results regarding non-farm 
impacts, and before we can create policies based on substantial empirical evidence, we must first provide a reliable direction for future studies to look into. My research question is a simple, but practical, one: where has non-farm activity occurred in exclusive farm use zones in the Northern Willamette Valley and are they clustered? The results I produce won't tell the whole story, but hopefully enough of one to spark greater interest from advocates, researchers, and policy makers alike. 


\section{Section III. Data and Methodology}

\section{Study Area}

The study area for this analysis was the Northern Willamette Valley (NWV) located in the northwest region of Oregon, comprised of Multnomah, Clackamas, Washington, Yamhill, Marion, and Polk County. The six NWV counties that hold 2.3 million people constitute the majority of the state's population (4.1 million), as well as a large concentration of Oregon’s high value farmland (United States Census Bureau’s Population Estimates Program, 2015). The co-existence of the state’s most productive farmlands and fastest growing cities makes the NWV an ideal region to examine nonfarm activity. Historically, the region has played a large role in shaping Oregon's statewide planning goals, particularly goal 3 to preserve agricultural lands. In 1973, concerns of urban encroachment into the Willamette Valley sparked the creation of senate bill 100 and the Land Conservation and Development Commission (LCDC) to formulate and balance Oregon's ten, now nineteen, state planning goals (DLCD, 2010; MacPherson \& Hallock, 1973). Thus, it was fitting that the Northern Willamette Valley served as the study area for practical and historical reasons as a nexus of the urban and agricultural contention and the embodiment Oregon’s land use planning success.

\section{Permit Data}

This study used permit approval data ranging from 1993 to 2015 from DLCD to determine where approved uses and dwellings are within EFU zones. The data provided the tax lot ID, county, year, and description of the permit. For dwellings, this description 
fell under one variable, “type”, while uses were identified by specific activities grouped within subcategories. Given the nature of permit data, each case represents an approved use or dwelling for a parcel in a specific point in time, and thus is not indicative of the current landscape. For example, a farm stand approved in 2003 does not mean that it will still be operational or even that the parcel it is sited on still exists. Additionally, the data do not encompass all non-farm activity that has occurred from 1993 to 2015, but only ones that have been tracked through the permit process. Despite these drawbacks, the data provide an extensive, but geographically precise, look into what has occurred in the region.

\section{Permitted Dwellings}

There are a total of seven different types of dwelling allowed within EFU zones: Accessory Farm Worker Housing, Dwelling Replacement, Lot of Record, Non-farm Dwellings, Primary Dwellings, Relative Farm Assistance, and Temporary Hardship. Below is a brief description of how these dwelling types are defined.

Accessory Farm Worker Housing: These dwellings are built on sites, whose primary operation is farming, for workers not related to the farm operator.

Dwelling Replacement: These dwellings replace an older home on a parcel. However, the permit data do not indicate what type of dwelling is being replaced or what it is being replaced with.

Lot of Record: Lot of records refer to special cases where a dwelling can be approved under the condition that the parcel has been under the same ownership prior to 1985. 
Non-farm Dwellings: These dwellings are approved on lands that are unsuitable for farm use. While non-farm dwellings may not directly, negatively impact the supply of productive farmlands, large concentrations of them may indirectly convert neighboring farmlands to other uses (DLCD, 2017).

Primary Dwellings: These dwellings are built on sites, whose primary operation is farming, for operators.

Relative Farm Assistance: These dwellings are built for relatives of the operator who will work on the farm. However, there is no requirement that the unit be occupied by a relative or remain farm related once the dwelling is constructed (DLCD, 2017). This oversight lends caution for one to assume that these dwellings are explicitly farm related and warrants further investigation.

Temporary Hardship: Temporary hardship dwellings refer to homes that are built concomitantly with a primary dwelling, farm related or not, to accommodate for a medical hardship endured by a family member. In theory, applicants are required to remove the dwelling at the end of the hardship term, but DLCD does not track these removals (DLCD, 2017). Contradictorily, it is possible that some temporary hardship dwellings are only temporary in name.

\section{Permitted Uses}

Uses varied more so than dwellings and contained over 60 different subcategories (Table 1). The majority of approved uses fell under commercial activities \& 
home occupations (36\%), Agri-tourism \& Wineries (14\%), and utility and energy

facilities (18\%) subcategories.

Table 1: Non-farm Use Subcategories

\begin{tabular}{|lll|}
\hline \multicolumn{3}{|c|}{ Subcategories } \\
\hline Accessory Use & Farm Related Building & Processing Facility \\
Agricultural building & Farm Stand & Public Facility \\
Agri-tourism & Flood Plain & Public park \\
Agri-tourism \& other commercial eve & Golf Course & Public Utility \\
AirStrip & Gun Club & Residence \\
AirStrip Overlay Expansion & Historic Res. Site & Road \\
Bed \& Breakfast & Home Occupation & Roads and Improvements \\
Bed and Breakfast & Horse Boarding & School \\
Cell Phone Facility & Land Fill & Sign \\
Cell Tower Facility & Landscape contracting business & Solar power generating facility \\
Church & Living history museum & Special Use \\
Comm. Act. & Min/Agg. & Telecommunication Facility \\
Commercial activities with farm use & Mineral/Aggregate & Temporary Use \\
Commercial Activity & Nonconforming use & Transmission Tower over 200 feet \\
Commercial Activity with Farm & Other & Utility Facility \\
Commercial Power Generating Facilit Other Use & Variance \\
Conditional Use & Park & Wastewater \\
Dog Kennel & Personal-use airport & Wind Energy Facility (Commercial) \\
Farm Exempt Bldg & Private Park & Winery \\
Farm Processing Facility & Private park/campground & With Nursey \\
\hline
\end{tabular}

"Commercial activities" refer to uses that are in conjunction with farm use, such as seed cleaning and fertilizer packaging, while "home occupations" tend to be more loosely related to farm use, ranging from meat processing to excavation and machine shop businesses. Specific uses falling under “Agri-tourism” ranged from farm stands, bed and breakfasts (B\&B), and agri-tourism events. “Utility and energy facilities” include cell towers, solar panels, wind turbines, and power stations.

Anecdotally, these subcategories and their specific uses do not appear to have been standardized, which created a variety of issues. Some of the subcategories were redundant, meaning there were multiple categories that overlapped one another. For example, there were four sub-categories for commercial activity: Comm. Act. , Commercial Activities with farm use, Commercial Activity, and Commercial Activity with Farm. While duplicate categories were more of an inconvenience, vis-a-vis 
summarizing data, inconsistent groupings of uses into sub-categories were more problematic and emblematic of the permits' data quality. For example, wineries fell under the following sub-categories: Agricultural Building, Commercial Activities, Golf Course, Home Occupation, and Winery. Finally, roughly 400 observations (out of 1,316 approved uses) needed to be removed entirely from our analysis because they were either one off activities or did not contain enough information that indicated there would be operation or development. Road repairs, bridge removals, and sign placements are examples of the former, while floodplain developments and wetland alterations are examples of the latter (appendix A).To clarify, most cases that fell under a floodplain development subcategory did not indicate the type of operation, let alone if the parcel was actually developed.

\section{Recoding the Data}

The wide range of allowed uses and dwellings called for the data to be recoded under three groups based on their relationship to farming: non-farm, distinct, and farm related. "Non-farm” uses and dwellings represented cases unrelated farming. "Distinct" uses and dwellings represented cases that are not explicitly farm related, whose impact on farming and farmland preservation are unknown. Agri-tourism, wineries, and utility facilities are distinct examples because the cumulative impacts of increased commercial activity, traffic, and, for the latter, transmission lines on neighboring farms are not fully understood (DLCD, 2017; Lehman, 2015). Similarly, dwelling replacements, relative farm assistance, and temporary hardship dwellings fall under the distinct group because they may not be explicitly farm related or, in the latter's case, temporary. "Farm related" uses and dwellings represent cases that are explicitly farm related. Table 2 provides 
examples of cases that fall within each group, though a full list can be found in appendix

A.

Table 2: Recoded Cases

\begin{tabular}{|c|l|l|}
\hline Group & \multicolumn{1}{|c|}{ Uses* } & \multicolumn{1}{c|}{ Dwellings } \\
\hline Non Farm & $\begin{array}{l}\text { Private Parks } \\
\text { Golf courses } \\
\text { Home Occupations } \\
\text { Mining/Aggregate } \\
\text { Schools }\end{array}$ & $\begin{array}{l}\text { Lot of record } \\
\text { Non Farm Dwelling }\end{array}$ \\
\hline \hline Distinct & $\begin{array}{l}\text { Agritourism } \\
\text { Wineries } \\
\text { Utility Facilities }\end{array}$ & $\begin{array}{l}\text { Dwelling Replacement } \\
\text { Temporary Hardship } \\
\text { Relative Farm Assistance }\end{array}$ \\
\hline \hline Farm Related & Processing Facilities & $\begin{array}{l}\text { Accessory Farm Worker } \\
\text { Housing } \\
\text { Primary Farm Dwelling }\end{array}$ \\
\hline
\end{tabular}

*For the full list of recoded farm uses, see appendix A

Recoding the data based on their relationship to farming achieved three things. First, flagging farm related cases allowed me to filter them out of the analyses, as I was only interested in identifying clusters of activity that potentially conflict with farming. Second, aggregating cases into groups increased their sample size, and subsequently, my chances of finding statistically significant clusters of activity. Finally, re-coding the farm use permits based their specific use addressed the aforementioned inconsistencies of how the data was originally categorized.

\section{Geocoding Permits}

I used the tax lot IDs (TLID) to geocode permits within the NWV. Geocoding refers to "transforming a description of a location—such as a pair of coordinates, an address, or a name of a place—-to a location on the earth's surface” (ESRI, 2017). Similar to a street addresses, the TLID is a composite field that can uniquely identify a parcel 
based on the county, township, range, section, and lot ID. Permits were plotted based on a TLID match with a spatial reference layer, or address locator, which contained all possible locations the permits could be sited on. For this study I used two spatial layers, the tax lot and Public Land Survey System (PLSS) shapefiles, to match the permits against. The PLSS dataset subdivides Oregon into grids by township, range, and section, in which the tax lot delineation is based on (Figure 1). Permits that did not match with the tax lot locator, either because of input error or the permits' parcel no longer exists, were paired against the more generalized PLSS layer at the section level to ascertain an approximate location.

Figure 1: PLSS \& Tax lot Shapefiles

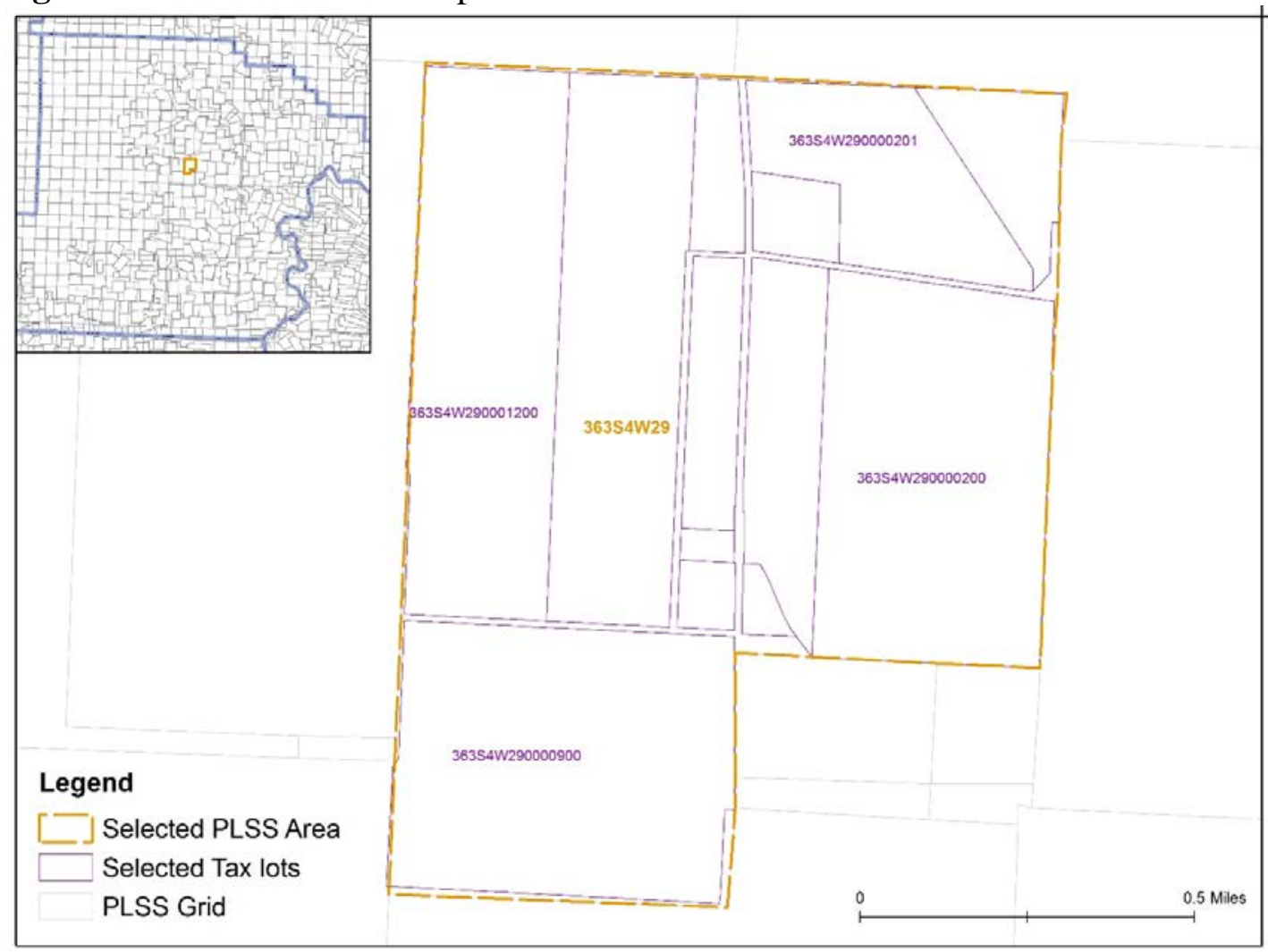

While the tax lot syntax was consistent amongst the permit data, it was structured differently than the TLID found in the tax lot and PLSS shapefiles. For the data to be 
matched to their corresponding locations, I created two standardized IDs: one that reflected the tax lot ID and the other to reflect the PLSS ID. I removed extraneous dashes, periods, and zeros to produce a new TLID and subsequently removed the "lot ID" characters to form a new PLSS ID (Table 3).

Table 3: Tax lot ID Structure

\begin{tabular}{|c|c|c|}
\hline Permit Tax Lot ID & New TLLD & PLSS ID \\
\hline 3603.00S04.00W2900--000000200 & 363S4W290000200 & 363S4W29 \\
\hline
\end{tabular}

There were 1,411 approved farm use permits and 3,764 approved farm dwelling permits in the NWV from 1993-2015. Geocoding results matched 874 of the 1,411 farm use permits and 2,418 of the 3,764 farm dwelling permits, resulting in 3,292 matches out of 5,175 total cases (Table 4). Of the 2,418 plotted dwelling permits, 1,654 cases (68\%) were perfectly geocoded to their corresponding parcel, while the remaining 764 cases (32\%) were plotted to an approximate location based on the PLSS centroid. Of the 874 plotted farm use permits, 518 cases (59\%) were perfectly geocoded to their corresponding parcel, while the remaining 356 cases (41\%) were geocoded to an approximate location based on the PLSS centroid. While the geocoding process was unable to match one-third of our permit data, 1,778 out of the 1,883 unmatched permits did not contain a tax lot ID, and thus could not be geocoded. Excluding cases that did not contain a tax lot ID, I was able to geocode 3,292 out of 3397 dwelling and use permits (97\%). I discuss the implications of the ungeocoded cases in the limitations section. 
Table 4: Geocoded Results (Not Cleaned)

\begin{tabular}{|l|c|c|c|}
\hline & Dwellings & Uses & Combined \\
\hline Total Cases & $\mathbf{3 7 6 4}$ & $\mathbf{1 4 1 1}$ & $\mathbf{5 1 7 5}$ \\
Matched Cases & $\mathbf{2 4 1 8}$ & $\mathbf{8 7 4}$ & $\mathbf{3 2 9 2}$ \\
TL match & 1654 & 518 & 2172 \\
PLSS match & $\mathbf{7 6 4}$ & 356 & 1120 \\
Unmatched & $\mathbf{1 3 4 6}$ & $\mathbf{5 3 7}$ & $\mathbf{1 8 8 3}$ \\
Unknown TLID & 1263 & 515 & 1778 \\
\hline
\end{tabular}

I cleaned the geocoded data by removing superfluous cases and reclassifying dwelling related cases incorrectly placed in the farm use dataset to the dwelling dataset. Permits were "superfluous" if they spatially intersected another point and contained the same TLID, year, and description. Of the 1,140 permits that overlaid another point, 45 cases shared an identical TLID, year, and activity with another permit and were subsequently flagged to be excluded from this study. Additionally, I found 95 "farm use" cases that were actually dwelling permits and moved them to the dwelling dataset. If the permits’ descriptions were too vague I classified them under “dwelling replacement.” Finally, I chose to exclude farm related cases from our analysis because I was not interested in tracking operations that are integral to farming practices.

Cleaning the data and selecting “distinct” and "non-farm” cases left 538 uses and 2126 dwellings to examine (Table 5). About one-third of the geocoded, non-farm cases were matched to their approximate location using the PLSS address locator, limiting my ability to perform the cluster analysis at the parcel, or point, scale. To account for this uncertainty, I aggregated permits to hexagonal grids, which served as the unit of analysis moving forward. 
Table 5: Geocoded Results (Cleaned)

\begin{tabular}{|l|c|c|c|}
\hline & Dwellings & Uses & Combined \\
\hline Total Cases & $\mathbf{3 8 5 9}$ & $\mathbf{1 3 1 6}$ & $\mathbf{5 1 7 5}$ \\
Matched Non & $\mathbf{2 1 2 6}$ & $\mathbf{5 3 8}$ & $\mathbf{2 6 6 4}$ \\
Farm Cases & & 336 & 1790 \\
$\quad$ TL match & 1454 & 336 \\
PLSS match & 672 & 202 & 874 \\
\hline
\end{tabular}

\section{Creating Hex Bins}

Spatial grids are advantageous to use for aggregation because they are uniform in size and reduce statistical biases that occur from irregularly shaped areal units, also known as the modifiable areal unit problem (MAUP). MAUP refers to distortions in the aggregated data that occur based on the arbitrary size or shape of an areal unit (Wong, 2009). Due to its uniformity, a spatial grid allows each point an equal chance to fall within a bin and, for this study, accounts for cases with approximate locations. I created hex bins at $3 / 4$ of a mile in area to reflect the median area of PLSS features that contained an imprecise geocoded permit (Appendix B). Hexagons that conformed with the following criteria served as the study area for the spatial analyses (Figure 2):

(1) Contains a permit point

(2) Intersects with EFU zoned land ${ }^{1}$

(3) Not inside a UGB, unless it contains a point

\footnotetext{
${ }^{1}$ Derived from the 2014 Oregon Zoning shapefile maintained by DLCD
} 
Figure 2: Hexagonal Grid (Study Area)

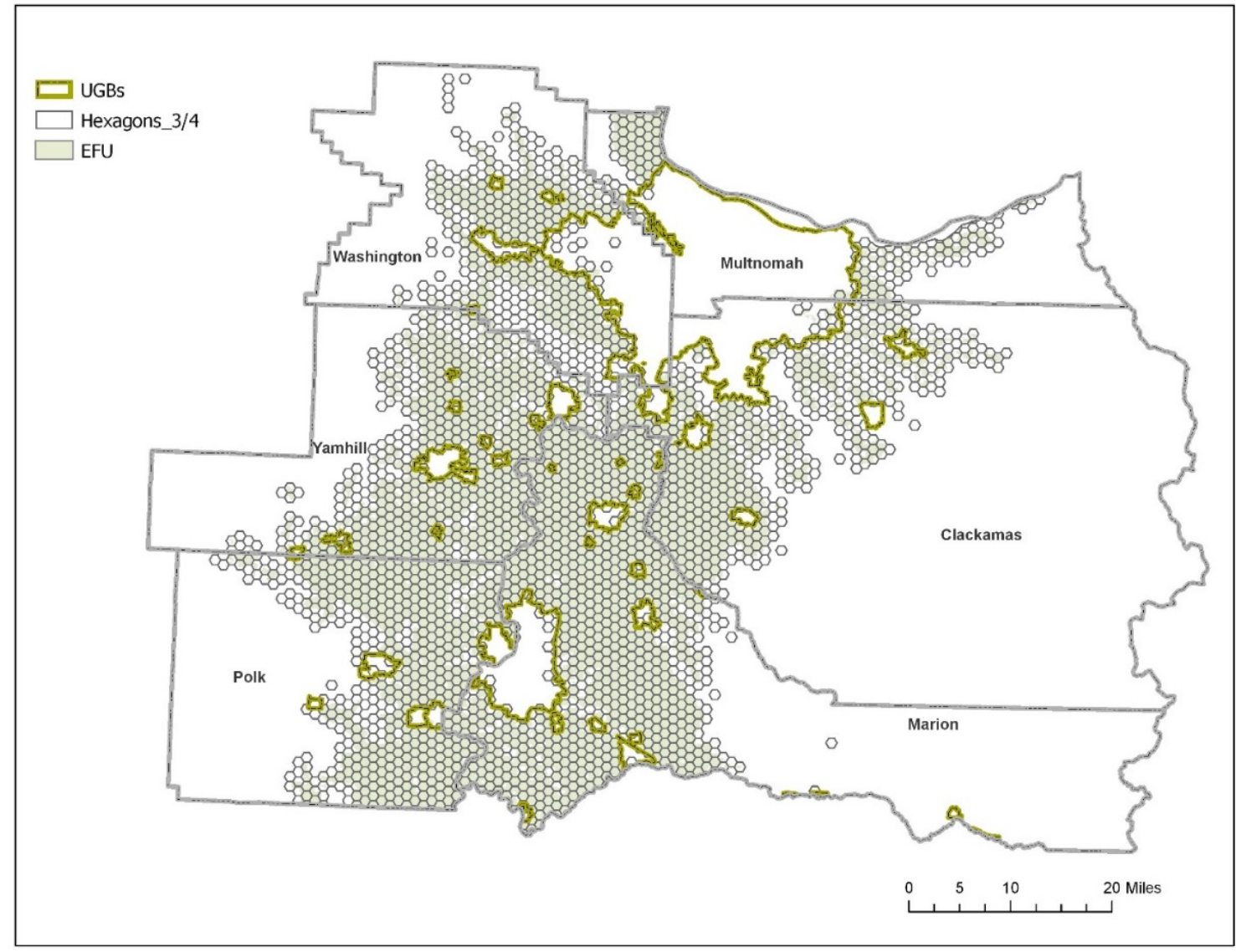

I aggregated permit points and tax lots to the hex grid based on the location of their centroid. Each hex contained information regarding the total count of all tax lots, the count of tax lots that contained a dwelling permit, and the count of tax lots that contained a use permit. With this information, I ran location quotient and spatial autocorrelation tests to determine where non-farm activity concentrated and clustered, respectively. This study operationalizes “concentration” and "cluster” as two separate, but related, processes. I define "concentration” as the presence of tax lots with a non-farm permit relative to the total number of tax lots, while "cluster" refers to contiguous hexagons that share similar concentrations. In particular, I am interested in identifying clusters where non-farm uses and dwelling are highly concentrated. 


\section{Location Quotient \& Spatial Autocorrelation (Anselin LISA)}

An area's location quotient (LQ) represents the concentration of a local industry in relation to a reference region (Miller \& Gibson, 1991). LQs have commonly been used to measure regional employment for cities/MSAs in relation to the United States, though this technique can be applied to non-farming activity (Flegg, Webber, \& Elliott, 1995; Miller \& Gibson, 1991; Wang \& Pandit, 2007). Conceptually, a location quotient normalizes the data to account for different group sizes that absolute counts would miss. For example, areas with higher instances of non-farm activity are not necessarily at risk of farmland conversion if there is also a large presence of farms. Figure 3 illustrates how location quotients quantify concentration mathematically. Coefficients greater than one $(>1)$ indicates the hexagon is more concentrated than what one would expect based on the crude density of the study area. On the other hand, LQs less than one $(<1)$ indicate a hexagon contains less concentrated activity. I calculated LQs for three separate datasets:

(1) distinct and non-farm dwellings, (2) distinct and non-farm uses, and (3) non-farm uses. I used these values for the local indicators of spatial association (LISA) test to measure clustering.

Figure 3: Location Quotient Employment (Industry) in Subarea/Total Employment in Subarea Employment (Industry) in US/Total Employment in US

Tax lots with a use|dwelling within hex/All tax lots within hex Tax lots with a use/dwelling within EFU/All tax lots within EFU 
As the name suggests, the LISA statistic identifies spatial clusters based on statistically significant associations amongst neighboring areal units (Anselin, 1995). The formula for calculating the local Moran’s I coefficient is as follows

$$
I_{i}=Z_{i} \sum_{j} w_{i j} Z_{j}
$$

where $Z_{i}$ and $Z_{j}$ represent deviations from the mean for the observed areal unit and other cases, respectively, and $\mathrm{W}_{\mathrm{ij}}$ represents a weighted adjacency matrix set to include neighboring values (Anselin, 1995). I defined an areal unit’s “neighbors” based on a shared vertex or edge with another polygon, also known as a queens contiguity weight (Anselin, 1995). This study focused on finding statistically significant, positive associations, or co-variances, for areal units and their neighbors. Positive associations come in the form of "hot spots" or "cold spots," where areal units and their neighbors collectively have higher than average estimates or lower than average estimates, respectively (Anselin, 1995). Hotspots, or statistically significant "high-high” areal units, represent locations where relatively high concentrations (LQs) of non-farm activity group together. In other words, a local Moran's I coefficient does not reflect the stand alone value of a hexagon, but rather its value in relation to the values of its contiguous neighbors and the study area as a whole (Figure 4). For our final step, I selected hexagons adjacent to High-High areal units at the 90\% confidence interval and analyzed similarities and differences between the permits within and outside our clusters. 
Figure 4: Hotspots \& Neighboring Areal Units

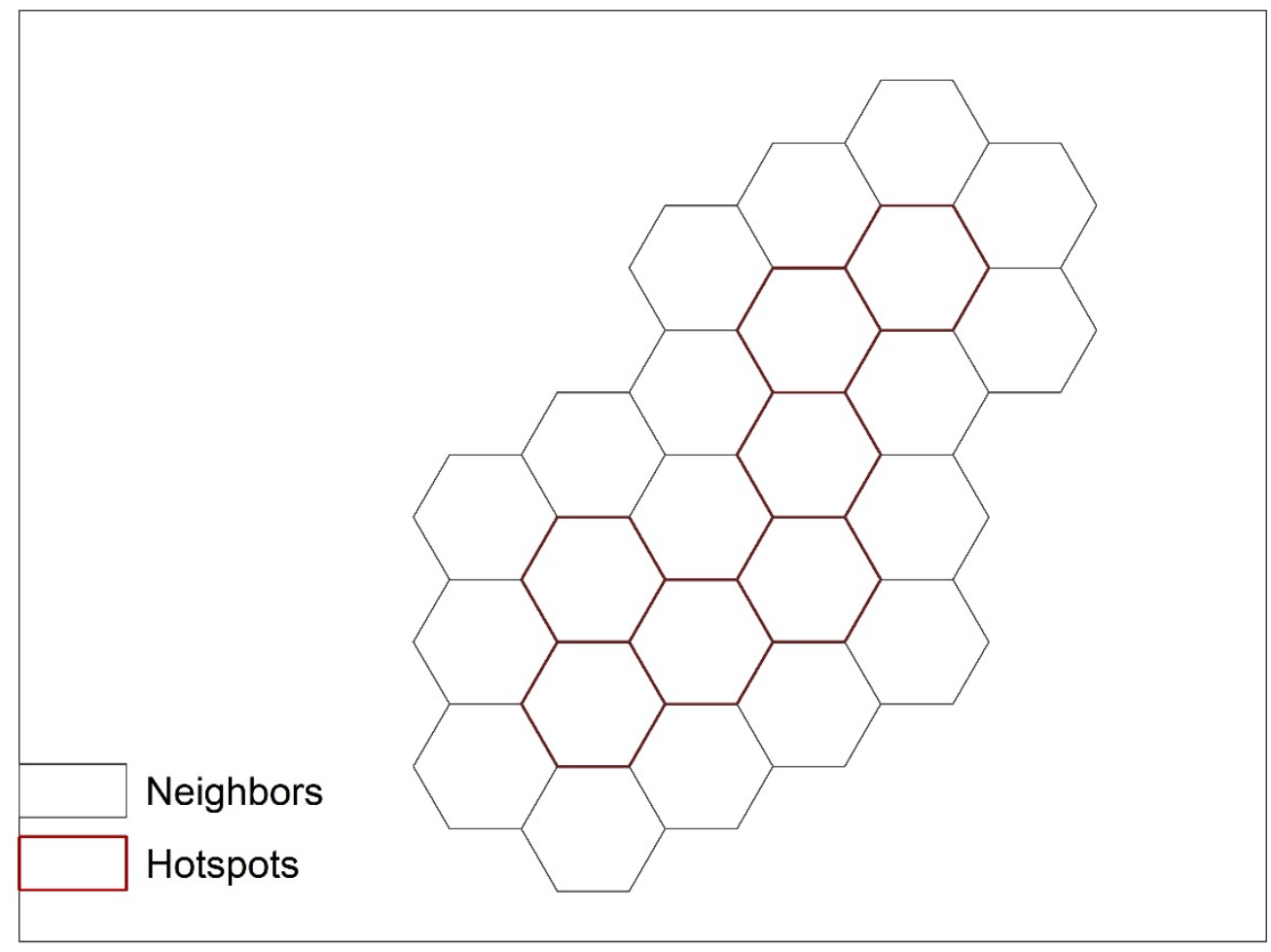

I repeated LQ and LISA tests twice for hexagonal grids $1 / 2$ mile and 1 mile in area.

The results of these ancillary datasets subjectively tested the sensitivity of my analysis.

By sensitivity, I mean the degree to which aggregated data and spatial patterns change based on different bin sizes. Highly sensitive analyses are problematic because their results are largely influenced by scale and boundaries more so than the underlying data. Some differences were expected, though consistent patterns of concentration and clustering across our datasets verify our results' resiliency to scale (Appendix B). 


\section{Section IV. Results}

\section{Summary of Geocoded Dwellings}

I geocoded 2,126 dwelling permits, which were not explicitly farm related, from 1993 to 2015 in the NWV (Table 6 \& Figure 5). The 1993-2000 period accounted for approximately one-third of the time frame, though a disproportionate number of dwellings, 1,023 (48\%), were approved during this span. In particular, $70 \%$ and $75 \%$ of relative farm assistance and lot of record dwellings were approved during this period, respectively. Since 2000, dwellings have increased 5\% per year on average though this is largely buoyed by dwelling replacements that have increased by $7 \%$ per year, while the annual growth rate for all other dwelling types varied from $2 \%$ to $4 \%$.

Table 6: Times Series Summary of Geocoded Dwellings

\begin{tabular}{|lcccc|}
\hline \multicolumn{4}{c}{ Geocoded Dwellings by Year } & \\
Total Dwellings & $\underline{2000}$ & $\underline{2005}$ & $\underline{2010}$ & $\underline{2015}$ \\
Dwelling Replacement & 1023 & 1336 & 1765 & 2126 \\
Lot Of Record & 415 & 624 & 885 & 1119 \\
Non Farm Dwellings & 157 & 174 & 192 & 209 \\
Relative Farm Assistance & 92 & 108 & 139 & 152 \\
Temporary Hardship & 83 & 88 & 102 & 118 \\
& 276 & 342 & 447 & 528 \\
& Share of Growth by Period & & \\
Total Dwellings & $1993-2000$ & $2001-2005$ & $2005-2010$ & $2011-2015$ \\
Dwelling Replacement & $48 \%$ & $15 \%$ & $20 \%$ & $17 \%$ \\
Lot Of Record & $37 \%$ & $19 \%$ & $23 \%$ & $21 \%$ \\
Non Farm Dwellings & $75 \%$ & $8 \%$ & $9 \%$ & $8 \%$ \\
Relative Farm Assistance & $61 \%$ & $11 \%$ & $20 \%$ & $9 \%$ \\
Temporary Hardship & $70 \%$ & $4 \%$ & $12 \%$ & $14 \%$ \\
Grand Total & $52 \%$ & $13 \%$ & $20 \%$ & $15 \%$ \\
\hline
\end{tabular}


Table 7 summarizes the geocoded dwelling permits by county. Marion County contained the plurality of dwelling cases, 576 (27\%), followed closely behind Washington County, 531 (25\%). Similarly, dwelling replacements made up the majority of dwelling units, 1,119 (53\%), of which a plurality were located in Washington and Marion County, 33\% and 31\% respectively. In fact, dwelling replacements made up at least a plurality of dwelling permits across all counties, save Clackamas County, which contained no geocoded cases of dwelling replacements.

Temporary hardship residences were the second largest dwelling type with a 528 (25\%) total cases. Marion County contained a plurality of temporary hardship cases (28\%), but a majority (57\%) of Clackamas’s dwelling permits consisted of temporary hardships. This concentration seems plausible as Clackamas is the oldest of the six counties with a median age of 41.5 in 2015 (United States Census Bureau's Population Estimates Program, 2015).

Lot of record permits totaled to 209 cases (10\%) with the plurality of cases falling into Yamhill County. Non-farm dwellings made up a smaller proportion of approved dwellings, 152 (7\%), with a plurality of cases concentrating in Marion County (31\%). Finally, relative farm assistance units comprised the smallest proportion of dwelling cases, 188 (5.5\%), with a plurality of cases concentrated in Clackamas County (29\%). 
Table 7: Summary of Geocoded Dwellings by County (Distinct \& Non-Farm)

\begin{tabular}{|c|c|c|c|c|}
\hline Dwelling Type & County & $\begin{array}{c}\text { Geocoded } \\
\text { Permits } \\
\end{array}$ & $\begin{array}{c}\% \text { of County } \\
\text { Dwellings }\end{array}$ & $\begin{array}{c}\% \text { of Dwelling } \\
\text { Type }\end{array}$ \\
\hline \multirow[t]{5}{*}{ Dwelling Replacement } & Marion & 346 & $60 \%$ & $31 \%$ \\
\hline & Multnomah & 29 & $64 \%$ & $3 \%$ \\
\hline & Polk & 242 & $59 \%$ & $22 \%$ \\
\hline & Washington & 369 & $69 \%$ & $33 \%$ \\
\hline & Yamhill & 133 & $42 \%$ & $12 \%$ \\
\hline \multirow[t]{6}{*}{ Lot Of Record } & Clackamas & 43 & $17 \%$ & $21 \%$ \\
\hline & Marion & 24 & $4 \%$ & $11 \%$ \\
\hline & Multnomah & 2 & $4 \%$ & $1 \%$ \\
\hline & Polk & 55 & $13 \%$ & $26 \%$ \\
\hline & Washington & 5 & $1 \%$ & $2 \%$ \\
\hline & Yamhill & 80 & $25 \%$ & $38 \%$ \\
\hline \multirow[t]{6}{*}{ Non Farm Dwellings } & Clackamas & 30 & $12 \%$ & $20 \%$ \\
\hline & Marion & 47 & $8 \%$ & $31 \%$ \\
\hline & Multnomah & 5 & $11 \%$ & $3 \%$ \\
\hline & Polk & 18 & $4 \%$ & $12 \%$ \\
\hline & Washington & 34 & $6 \%$ & $22 \%$ \\
\hline & Yamhill & 18 & $6 \%$ & $12 \%$ \\
\hline \multirow[t]{6}{*}{ Relative Farm Assistance } & Clackamas & 34 & $14 \%$ & $29 \%$ \\
\hline & Marion & 13 & $2 \%$ & $11 \%$ \\
\hline & Multnomah & 7 & $16 \%$ & $6 \%$ \\
\hline & Polk & 24 & $6 \%$ & $20 \%$ \\
\hline & Washington & 18 & $3 \%$ & $15 \%$ \\
\hline & Yamhill & 22 & $7 \%$ & $19 \%$ \\
\hline \multirow[t]{6}{*}{ Temporary Hardship } & Clackamas & 139 & $57 \%$ & $26 \%$ \\
\hline & Marion & 146 & $25 \%$ & $28 \%$ \\
\hline & Multnomah & 2 & $4 \%$ & $0 \%$ \\
\hline & Polk & 70 & $17 \%$ & $13 \%$ \\
\hline & Washington & 105 & $20 \%$ & $20 \%$ \\
\hline & Yamhill & 66 & $21 \%$ & $13 \%$ \\
\hline
\end{tabular}


Figure 5: Geocoded Dwellings (Distinct \& Non-Farm)

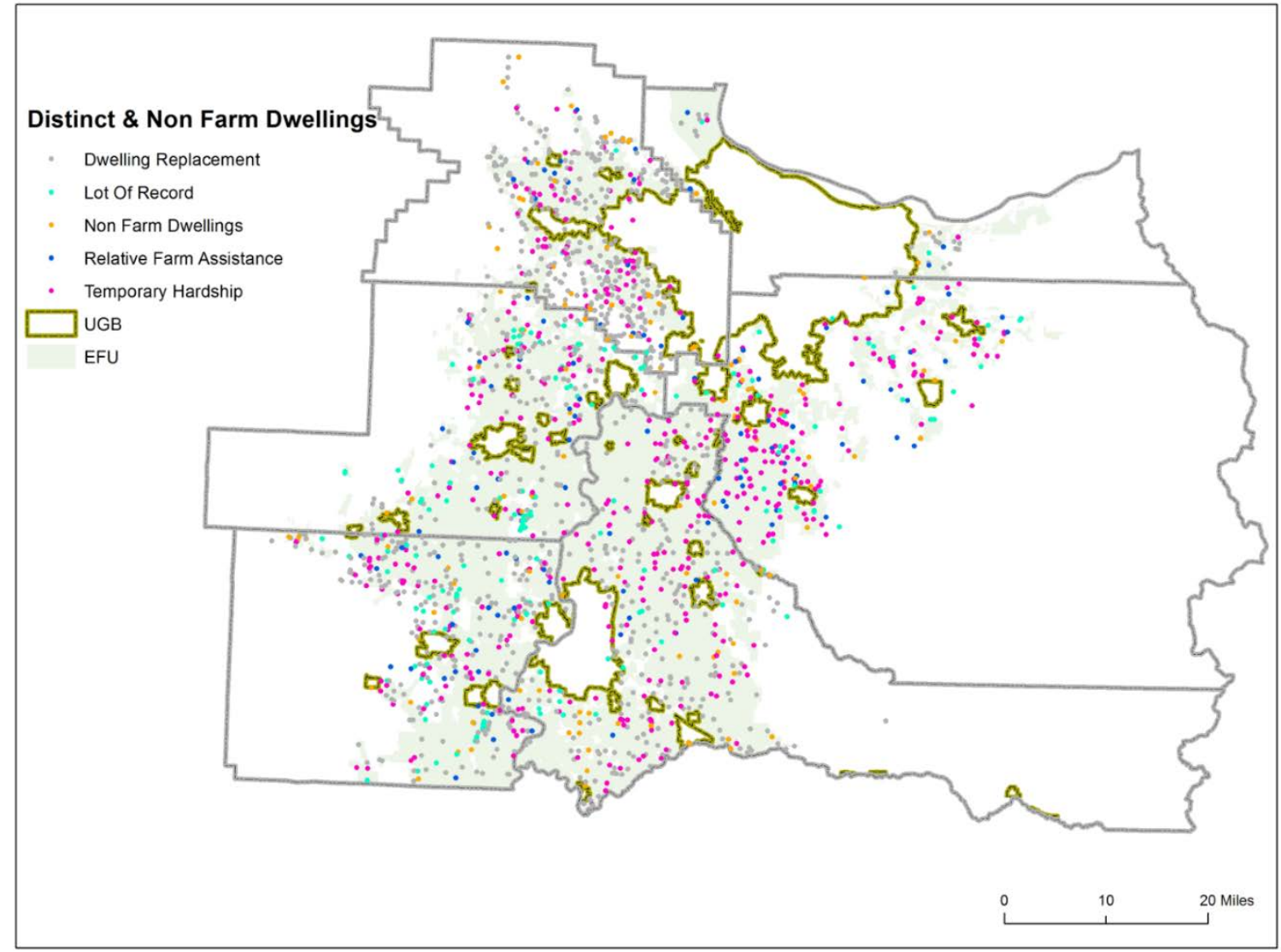

Figure 6 illustrates location quotients for dwelling activity. Areal units whose

density was less that the density of the study area are blank. Hexagons that had a density between 1 to 2 times that of the study area are grey. Areas darker shades of purple indicate a greater concentration relative to the study area. 
Figure 6: Location Quotients for Geocoded Dwellings (Distinct \& Non-Farm)

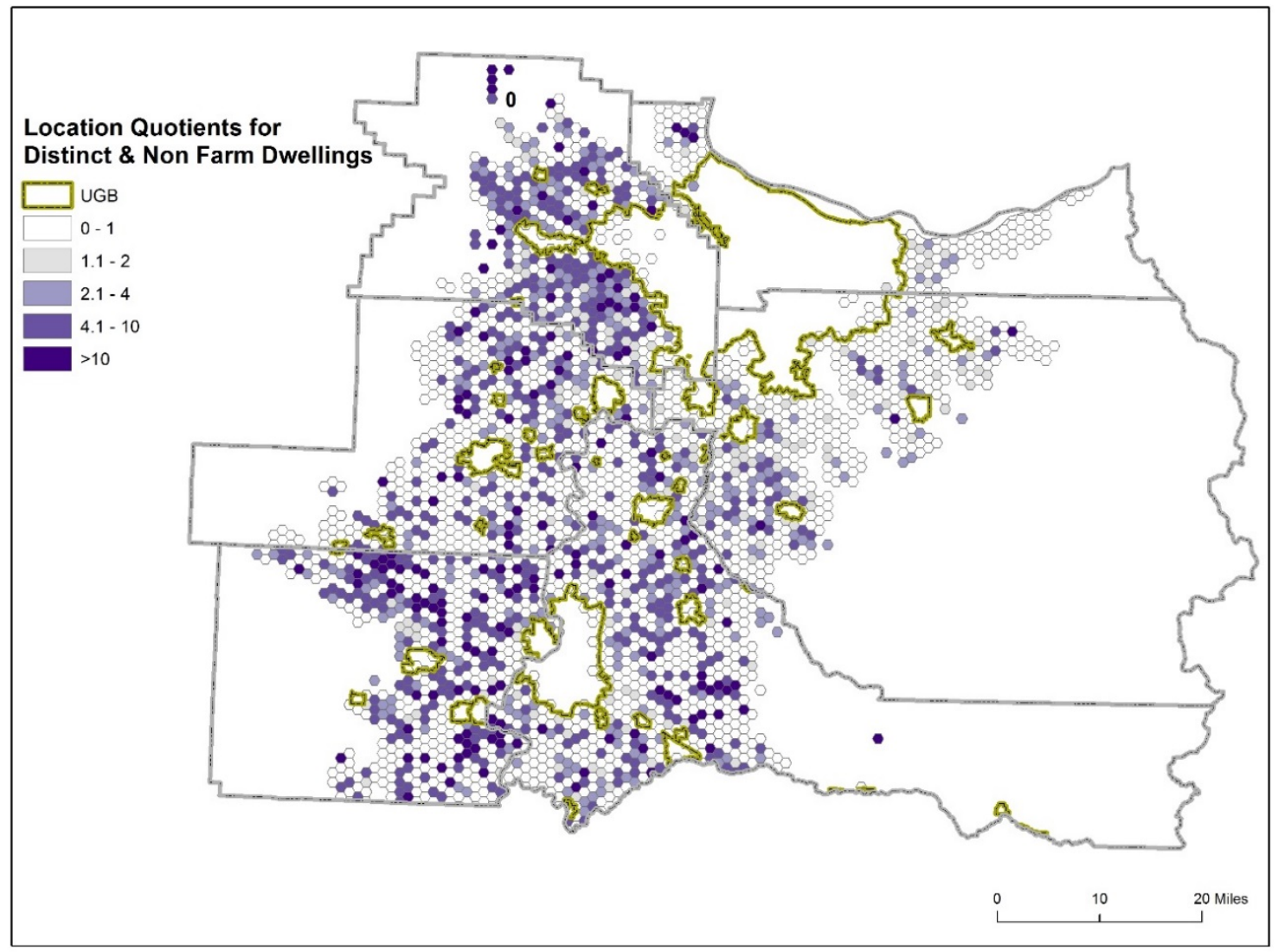

The LISA analysis using the LQ coefficients revealed 59 statistically significant "High-High" hexagons at the 95\% confidence interval and 11 hexagons at the 90\% confidence interval (Figure 7). The 254 hexagons adjacent to the hotspots formed my cluster study area, which made up 9\% of the total hexagonal grid. Interestingly, Clackamas County was the only county that did not have any statistically significant hotspots. 415 out of 2,126 dwellings, nearly twenty percent (19.5\%), fell within the statistically significant hotspots that only composed of $9 \%$ of the study area. I subjectively identified five distinct groups of clusters, excluding group 0 , based on dwelling makeup and proximity to other hexagons (Figure 7). 
Figure 7: Hotspots for Geocoded Dwellings (Distinct \& Non-Farm)

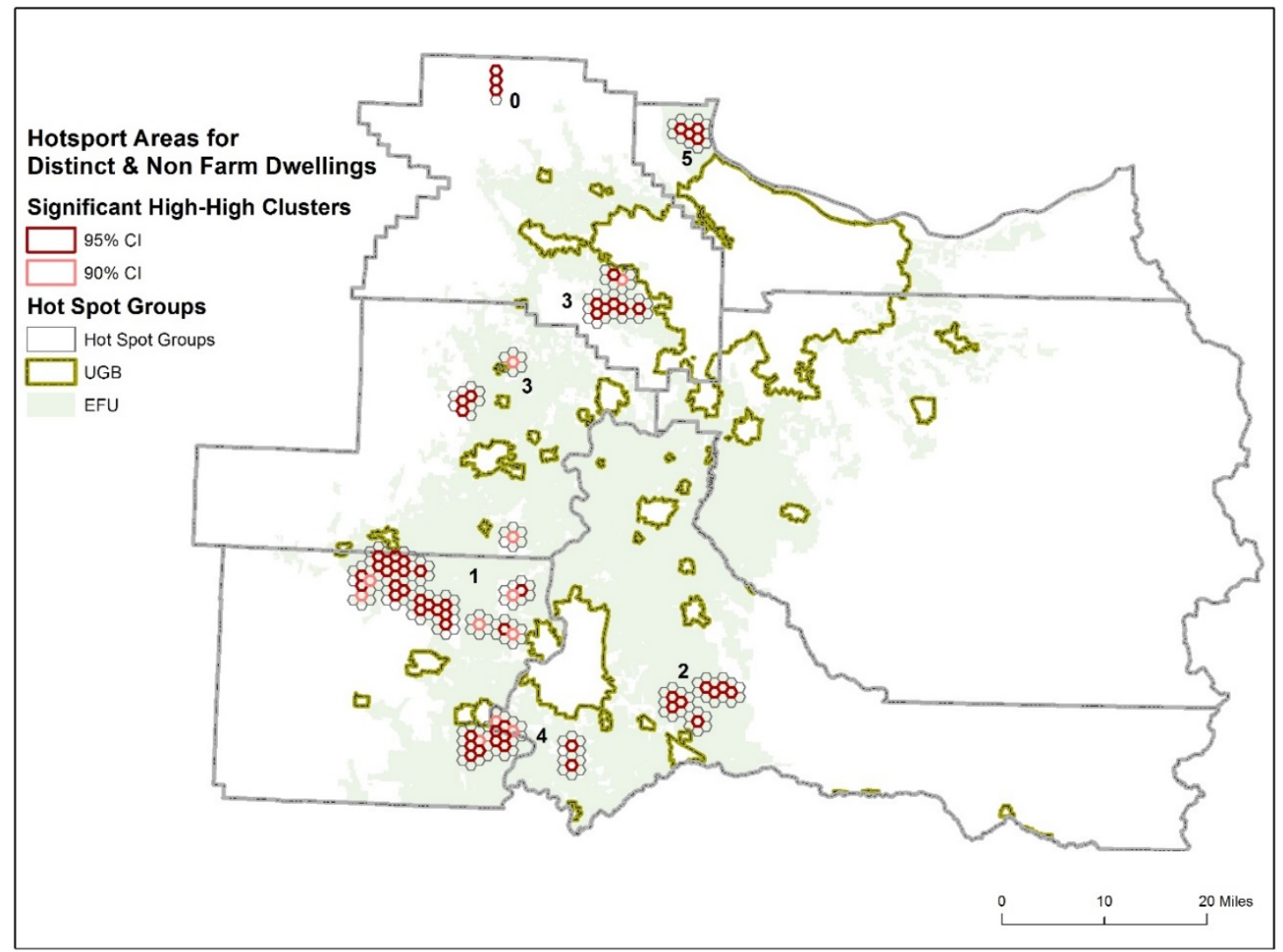

Table 8 summarizes the breakdown of dwellings by cluster group. Similar to the study area as a whole, dwelling replacements comprised the majority of dwellings, 213 (51\%), within our cluster study area. The plurality of cases fell within groups 1 and 3, located near the Yamhill/Polk and Washington/Yamhill boundary, respectively. Dwelling replacements roughly made up the majority of dwelling cases within groups 1 and 3 , which collectively accounted for $14 \%$ (of the $19 \%$ ) of all replacement dwelling cases.

Lot of record cases were more clustered than total dwellings on average, as $31 \%$ (64) of all lot of record cases fell within our cluster study area compared to the $19.5 \%$ for all dwellings. Most of the lot of record cases fell within group 1, which contained $20 \%$ of all lot or record cases, followed by group 4 . 
Non-farm dwellings were less clustered than total dwellings on average with only $15 \%$ (24) of cases falling within our hotspot groups. Group 4 contained the plurality of non-farm dwellings that fell within our cluster study area (11\%).

Relative farm assistance dwellings were also less clustered than total dwellings on average with only 14\% (17) of cases falling within our cluster study area. Group 1 contained the plurality of relative farm assistance dwellings at roughly $7 \%$.

Temporary hardship dwellings clustered in a similar intensity relative to all dwellings on average with 19\% (98) of cases falling within our hotspots. Interestingly, Clackamas and Marion County contained the majority of all hardship cases, 285 out of 528, but group 3, located near the Washington/Yamhill county boundary, and contained the plurality of clustered hardship cases (9\%). 
Table 8: Summary of Dwelling Hotspots (Distinct \& Non-Farm)

\begin{tabular}{|c|l|c|c|c|}
\hline \multirow{2}{*}{ Cluster Group } & \multicolumn{1}{|c|}{ Dwelling Type } & $\begin{array}{c}\text { Geocoded } \\
\text { Permits }\end{array}$ & $\begin{array}{c}\% \text { of Cluster } \\
\text { Group }\end{array}$ & $\%$ of Type \\
\hline 0 & Dwelling Replacement & 5 & $63 \%$ & $0 \%$ \\
& Non Farm Dwellings & 1 & $13 \%$ & $1 \%$ \\
& Temporary Hardship & 2 & $25 \%$ & $0 \%$ \\
\hline 1 & Dwelling Replacement & 74 & $47 \%$ & $7 \%$ \\
& Lot Of Record & 42 & $26 \%$ & $20 \%$ \\
& Non Farm Dwellings & 6 & $4 \%$ & $4 \%$ \\
& Relative Farm Assistance & 8 & $5 \%$ & $7 \%$ \\
& Temporary Hardship & 29 & $18 \%$ & $5 \%$ \\
\hline 2 & Dwelling Replacement & 17 & $63 \%$ & $2 \%$ \\
& Non Farm Dwellings & 2 & $7 \%$ & $1 \%$ \\
& Temporary Hardship & 8 & $30 \%$ & $2 \%$ \\
\hline 3 & Dwelling Replacement & 74 & $53 \%$ & $7 \%$ \\
& Lot Of Record & 9 & $6 \%$ & $4 \%$ \\
& Non Farm Dwellings & 6 & $4 \%$ & $4 \%$ \\
& Relative Farm Assistance & 3 & $2 \%$ & $3 \%$ \\
& Temporary Hardship & 48 & $34 \%$ & $9 \%$ \\
\hline 4 & Dwelling Replacement & 38 & $53 \%$ & $3 \%$ \\
& Lot Of Record & 12 & $17 \%$ & $6 \%$ \\
& Non Farm Dwellings & 8 & $11 \%$ & $5 \%$ \\
& Relative Farm Assistance & 4 & $6 \%$ & $3 \%$ \\
& Temporary Hardship & 10 & $14 \%$ & $2 \%$ \\
\hline \multirow{2}{*}{5} & Dwelling Replacement & 5 & $56 \%$ & $0 \%$ \\
& Lot Of Record & 1 & $11 \%$ & $0 \%$ \\
& Relative Farm Assistance & 2 & $22 \%$ & $2 \%$ \\
& Temporary Hardship & 1 & $11 \%$ & $0 \%$ \\
\hline
\end{tabular}

In summary, the cluster analysis revealed a few idiosyncrasies in the data worth mentioning. First, Marion County contained the plurality of all dwelling cases, 27\%, but only contained $16 \%$ of clustered cases. On the other hand, Polk County, which was behind Marion and Washington County in total number of dwelling cases, contained 40\% of clustered cases in large part to groups 1 and 4. Second, Clackamas County deviated from the other counties in many ways. Clackamas was the only county to not have a single dwelling replacement case, geocoded or ungeocoded. It is possible that the county 
reclassifies dwelling replacement permits to one of other 6 dwelling types, though I have not verified this. Additionally, Clackamas has a disproportionate number of relative assistance and temporary hardship dwellings, but these do not appear to be clustered based on my approach. Lastly, dwelling replacement cases did not clarify the dwelling type of new residences, leading one to speculate on the nature of this omission. It is possible that these residences are randomly distributed amongst the 6 other dwelling types, though it is equally possible that a disproportionate number could be non-farm dwellings. This question is beyond the scope of this study, but warrants further investigation.

\section{Summary of Geocoded Uses}

I geocoded 538 use permits, which were not explicitly farm related, from 1993 to 2015 in the NWV (Table 9 \& Figure 8). Due to the wide variety of uses, I broke down my analysis based on the relationship (to farming) group. Unlike dwellings, uses grew steadily over time, as roughly one-third of cases were approved within the first third of the 1993-2015 time frame. However, non-farm uses grew slightly faster before 2001, while growth for distinct cases has gradually increased since then in large part to agritourism and viticulture operations. Overall, uses have grown at a slightly faster rate than dwellings since 2000 , $8 \%$ per year on average, though some of this is impacted by the data’s denominators (538 vs 2,126). 
Table 9: Time Series Summary of Geocoded Uses

\begin{tabular}{|ccccc|}
\hline \multicolumn{5}{c}{ Geocoded Uses by Year } \\
Total Uses & $\underline{2000}$ & $\underline{2005}$ & $\underline{2010}$ & $\underline{2015}$ \\
Non-Farm & 186 & 277 & 401 & 538 \\
Distinct & 101 & 147 & 212 & 264 \\
& 85 & 130 & 189 & 274 \\
& Share of Growth by Period & \\
Total Uses & $1993-2000$ & $\underline{2001-2005}$ & 2005-2010 & 2011-2015 \\
Non-Farm & $35 \%$ & $17 \%$ & $23 \%$ & $25 \%$ \\
Distinct & $38 \%$ & $17 \%$ & $25 \%$ & $20 \%$ \\
\hline
\end{tabular}

Table 10 summarizes the geocoded uses by county. Marion county contained the plurality of use cases, 232 (43\%), followed by Washington County, 109 (18\%). Distinct cases, or uses whose impact on farming production and preservation are unknown, made up made up the majority of use cases for all counties, except Marion and Multnomah County.

Distinct uses for Washington, Polk, and Marion County were generally split between agri-tourism/viticulture, including wineries (with our without golf courses) and farm stands, and facilities \& energy, including cell towers, wind turbines, and sub stations (Figure 15). For Yamhill County, 80\% of farm use cases were “distinct” in large part to its high concentration of viticulture industries. Clackamas County did not contain many distinct uses, though 23 out of 25 of its cases were cell towers. Similarly, Multnomah County had the fewest number of cases amongst all counties, though there was permit activity near Sauvie Island, a center for many agri-tourism events (Lehman, 2015). 
Table 10: Summary of Geocoded Uses (Distinct \& Non-Farm)

\begin{tabular}{|l|l|ccc|}
\hline \multirow{2}{*}{ Use Group } & \multicolumn{1}{|c|}{ County } & $\begin{array}{c}\text { Geocoded } \\
\text { Permits }\end{array}$ & $\begin{array}{c}\% \text { of County } \\
\text { Uses }\end{array}$ & \% of Use Group \\
\hline Total & Clackamas & 40 & -- & $7 \%$ \\
& Marion & 232 & -- & $43 \%$ \\
& Multnomah & 16 & -- & $3 \%$ \\
& Polk & 44 & -- & $8 \%$ \\
& Washington & 109 & -- & $20 \%$ \\
& Yamhill & 97 & -- & $18 \%$ \\
\hline Non Farm & Clackamas & 15 & $38 \%$ & $6 \%$ \\
& Marion & 153 & $66 \%$ & $58 \%$ \\
& Multnomah & 9 & $56 \%$ & $3 \%$ \\
& Polk & 19 & $43 \%$ & $7 \%$ \\
& Washington & 49 & $45 \%$ & $19 \%$ \\
& Yamhill & 19 & $20 \%$ & $7 \%$ \\
\hline & Clackamas & 25 & $63 \%$ & $9 \%$ \\
& Marion & 79 & $34 \%$ & $29 \%$ \\
& Multnomah & 7 & $44 \%$ & $3 \%$ \\
& Polk & 25 & $57 \%$ & $9 \%$ \\
& Washington & 60 & $55 \%$ & $22 \%$ \\
& Yamhill & 78 & $80 \%$ & $28 \%$ \\
\hline
\end{tabular}

Non-farm cases varied amongst counties moreso than distinct cases did, and consisted of private parks, dog kennels, and churches to name a few. Home occupations and commercial activities made up the bulk of non-farm observations, 160 out of 264 cases (61\%), with Marion County as the prime example. 117 out of 153 (76\%) of Marion County’s non-farm cases were home occupations or commercial activities, which collectively accounted for $58 \%$ of all geocoded cases for the respective subgroup. 
Figure 8: Geocoded Uses (Distinct \& Non-Farm)

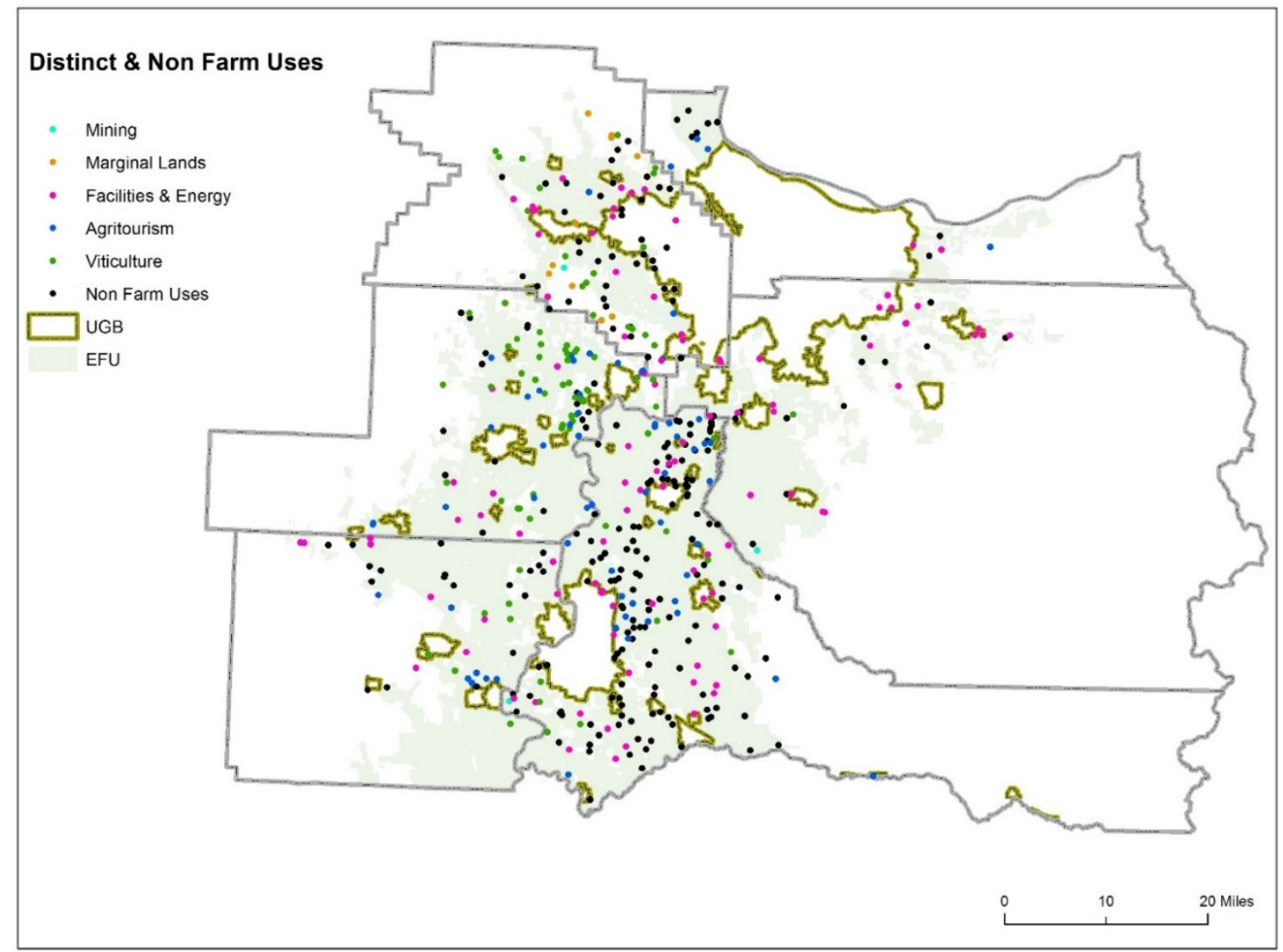

Figure 9 represents location quotients for distinct and non-farm uses. Hexagons

with a LQ less than 1 indicate that dwelling activity is less concentrated relative to the EFU area as a whole and are colored blank. Areas with concentrations between 1 to 2 times that of the study area are colored grey. Areas with greater concentrations correspond to darker shades of purple. The most highly concentrated areas are located near the Yamhill/Marion County border and in the center of Marion County. 
Figure 9: Location Quotients for Geocoded Uses (Distinct \& Non-Farm)

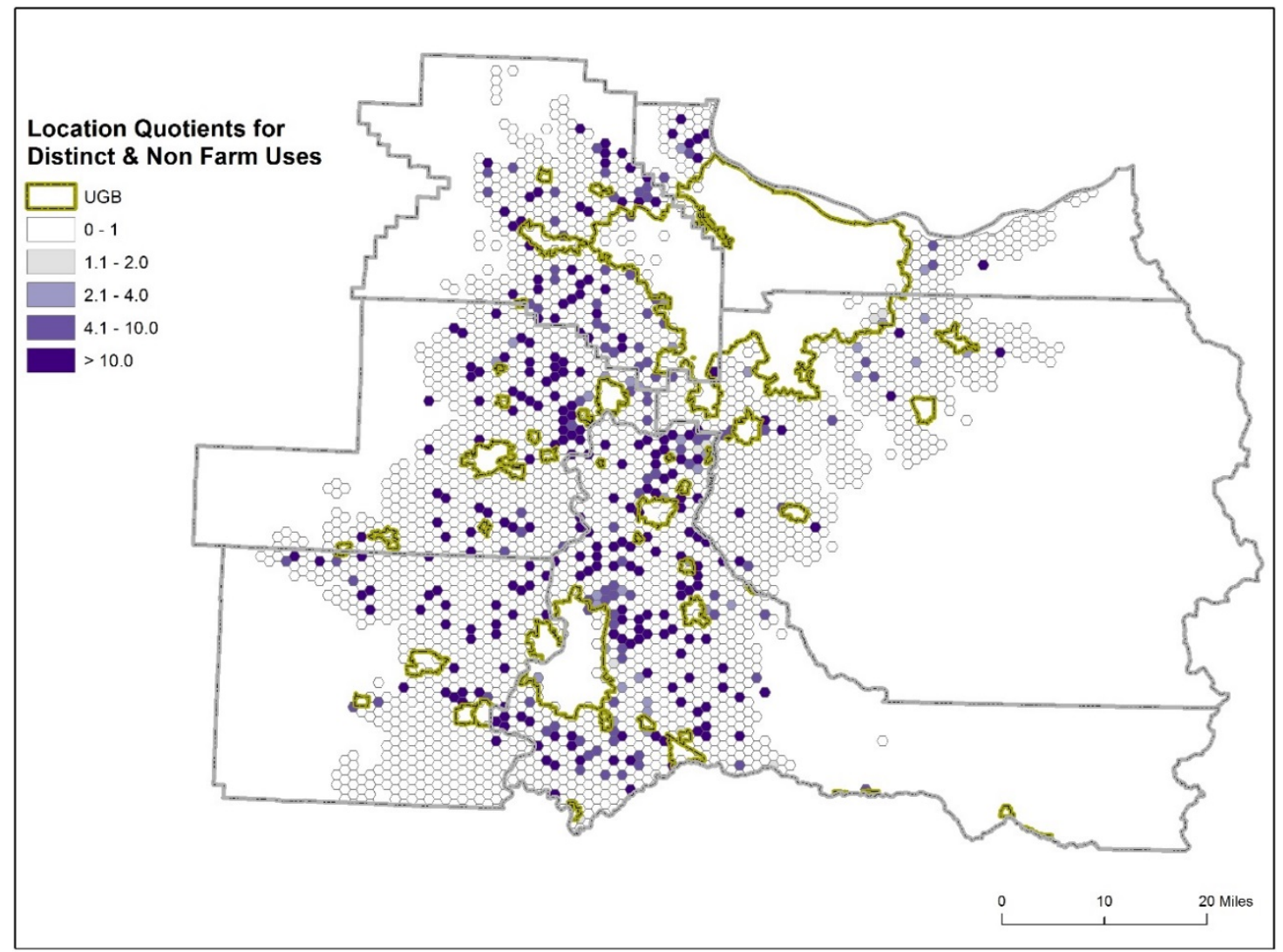

The univariate LISA test revealed 51 statistically significant "High-High"

hexagons at the $95 \%$ confidence interval and 8 hexagons at the $90 \%$ confidence interval (Figure 10). The 245 hexagons adjacent to the hotspots formed my cluster study area, which made up $8 \%$ of our study area. Like the dwelling results, Clackamas County did not contain any statistically significant clusters. 140 out of 538 uses, about a quarter of cases (26\%), fell within these hotspots that only made up $8 \%$ of the hexagonal study area. As noted above, the majority of uses (distinct \& non-farm) fell under the following activities: commercial activities \& home occupations, agri-tourism \& wineries, and utility and energy facilities. This was the case as well within the cluster groups; roughly threequarters of cases, 110 out of 140 (78\%), fell under those three groups (Appendix A). Nearly a quarter (24\%) of all commercial activity \& home occupation cases fell within 
one of the clusters. Of the 71 geocoded agri-tourism related cases, 30 cases (42\%) fell within the cluster study area. Viticulture cases also concentrated to a similar degree; nearly half of all cases, 38 out of 82 (46\%), were within a hotspot. Facilities and energy stations were more sporadic than other uses; only 13 of the 108 cases were located within a cluster. I subjectively identified 6 distinct groups, excluding “0”, based on use makeup and proximity to other hexagons (Figure 10).

Figure 10: Hotspots for Geocoded Uses (Distinct \& Non-Farm)

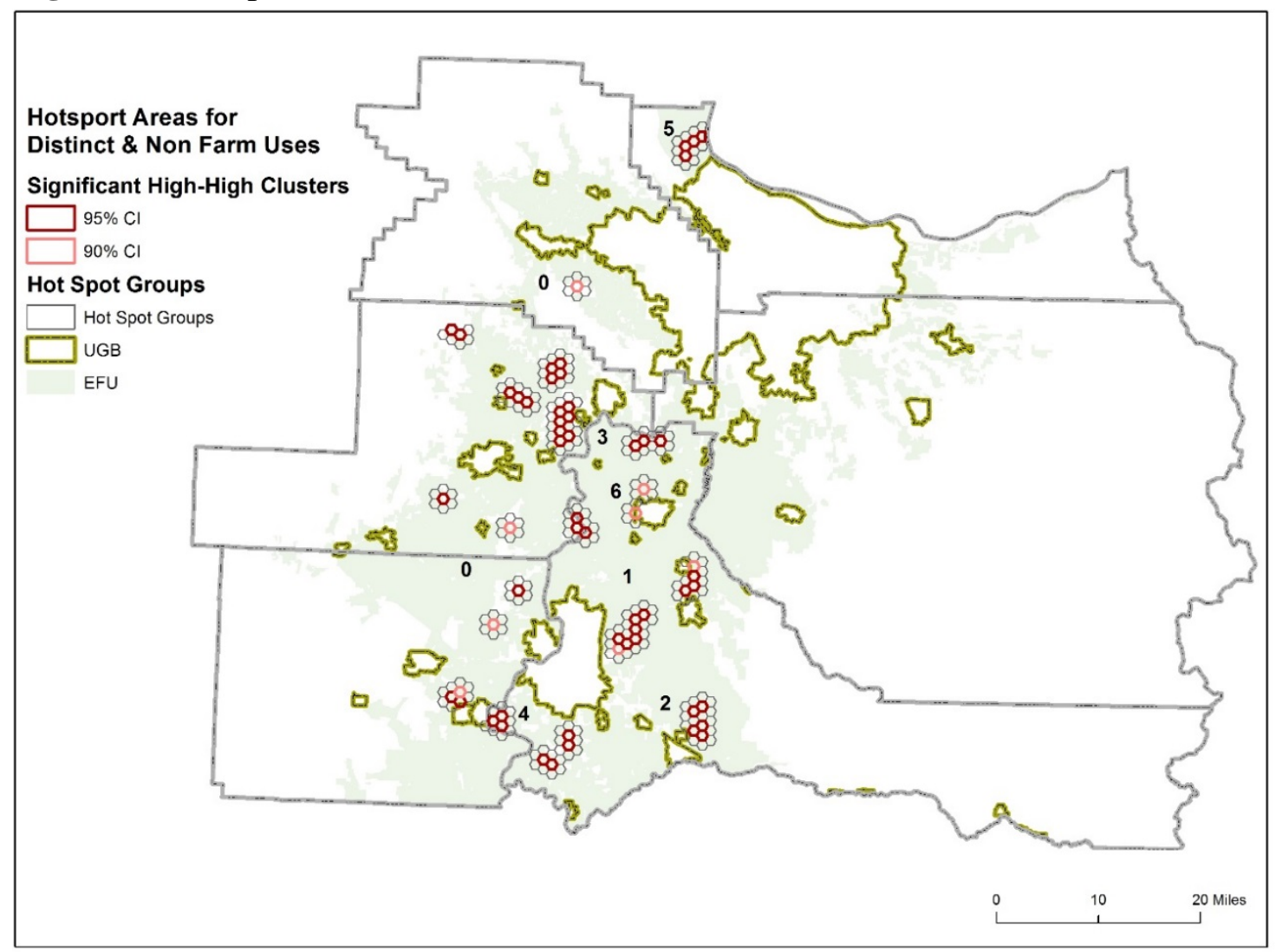

Table 11 summarizes the breakdown of uses by cluster group. Group 0 represents clusters that am Isolated and/or contain too few cases to summarize. Group 1 is located in the central region of Marion County near the Salem-Keizer and Silverton UGB. Group 1 is the second largest cluster, containing the plurality of non-farm uses that amounted to $7 \%$ of all geocoded non-farm cases. Group 2 is located in the southern portion of Marion 
County near Stayton. This group contained the second fewest number of cases, 7, with a majority of uses falling under home occupation. Group 3, located on the Yamhill/Marion County border near the Newberg and Dundee UGB, is the largest cluster containing the plurality of distinct cases, nearly all of which were related to viticulture and agri-tourism.

Group 4 is near the southern portion of the Polk/Marion border in proximity to the Monmouth, Independence, and Salem-Keizer UGBs. The majority of cases within this cluster were home occupations and commercial activities. Group 5 contained the fewest number of cases located in the northwest region of Multnomah County near Sauvie Island, a popular agri-tourism destination (Lehman, 2015). Group 6, located just outside of Woodburn in northern Marion County, is mainly comprised of commercial activities/home occupations and utilities.

Table 11: Summary of Use Hotspots (Distinct \& Non-Farm)

\begin{tabular}{|c|c|c|c|c|}
\hline Cluster Group & Use Group & $\begin{array}{c}\text { Geocoded } \\
\text { Permits }\end{array}$ & $\begin{array}{c}\% \text { of Cluster } \\
\text { Group }\end{array}$ & $\%$ of Type \\
\hline 0 & Non Farm & 7 & $37 \%$ & $3 \%$ \\
& Distinct & 12 & $63 \%$ & $4 \%$ \\
\hline \multirow{2}{*}{1} & Non Farm & 19 & $59 \%$ & $7 \%$ \\
& Distinct & 13 & $41 \%$ & $5 \%$ \\
\hline 2 & Non Farm & 5 & $71 \%$ & $2 \%$ \\
& Distinct & 2 & $29 \%$ & $1 \%$ \\
\hline 3 & Non Farm & 8 & $17 \%$ & $3 \%$ \\
& Distinct & 38 & $83 \%$ & $14 \%$ \\
\hline 4 & Non Farm & 8 & $42 \%$ & $3 \%$ \\
& Distinct & 11 & $58 \%$ & $4 \%$ \\
\hline 5 & Non Farm & 4 & $67 \%$ & $2 \%$ \\
& Distinct & 2 & $33 \%$ & $1 \%$ \\
\hline 6 & Non Farm & 7 & $64 \%$ & $3 \%$ \\
& Distinct & 4 & $36 \%$ & $1 \%$ \\
\hline
\end{tabular}

In summary, the cluster analysis revealed a few patterns worth mentioning. First, Marion and Washington contained the most distinct and non-farm uses as a whole, but cases in the former were much more clustered than the latter. Second, commercial 
activities and home occupations made up the majority of use cases for all hotspots except group 3, which primarily contained viticulture cases, and group 5, which had the fewest cases. Third, utility facilities, such as energy stations and cell towers, do not appear to be clustered, though they are still worth monitoring should energy intensive uses multiply within EFU zones. Lastly, after I removed distinct cases, non-farm uses were clustered in similar locations in Marion County (Figure 11). Like the previous analysis, the majority of cases were home occupations and commercial activities.

Figure 11: Hotspots for Geocoded Non-Farm Uses

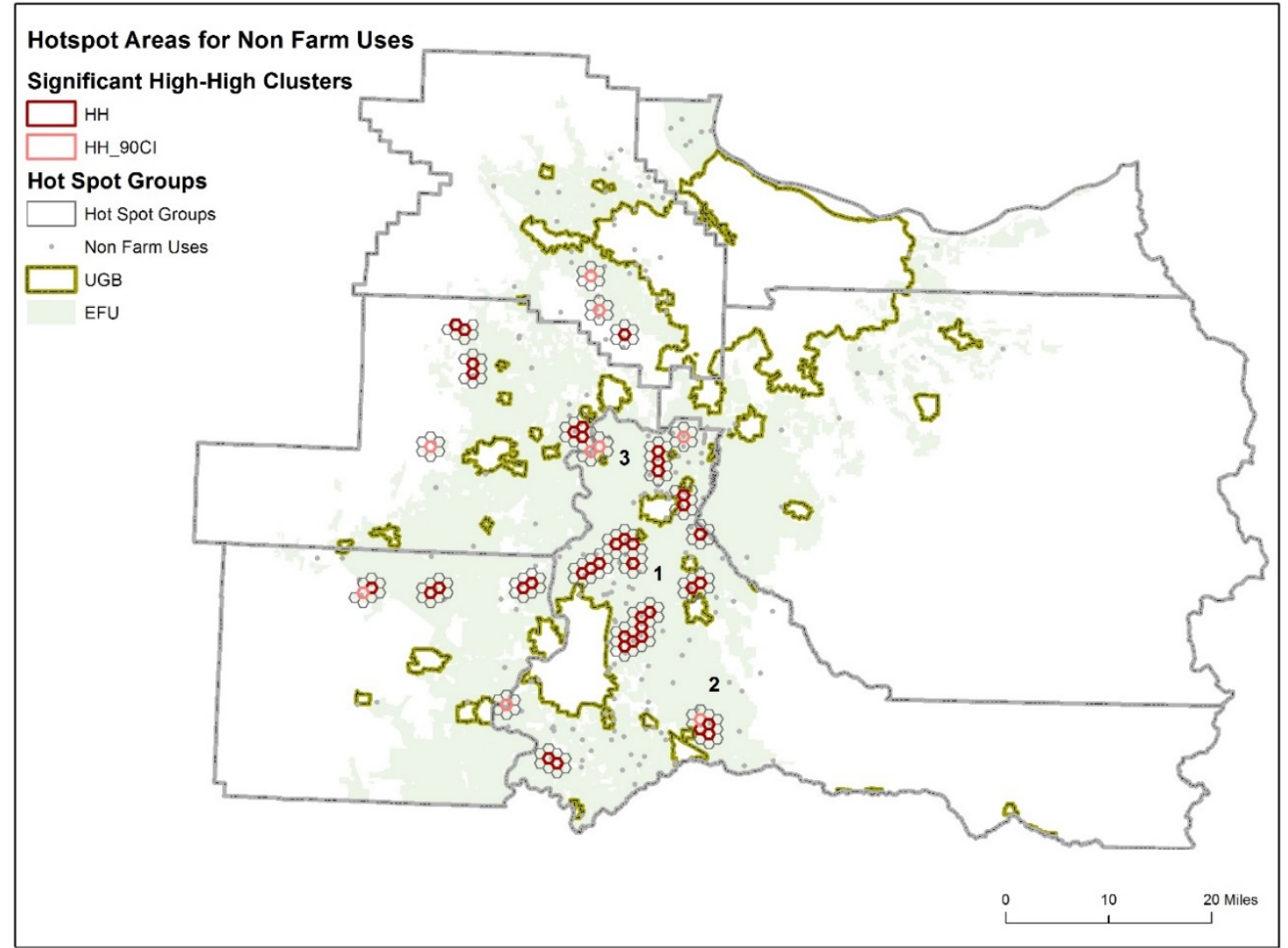




\section{Section V. Discussion}

The purpose of this study is to provide a more detailed look at how non-farm related developments have proliferated and clustered in the Northern Willamette Valley and determine on where these activities have clustered. Previous studies have raised concerns regarding the effect of conflicting uses on farmland productivity and preservation. Specifically, advocates are interested in the cumulative impacts that may adversely or beneficially affect the agricultural economy. On the one hand, non-farm uses and dwellings can provide supplementary incomes for smaller farms and/or maximize the efficiency of less productive land that would otherwise go unused. On the other hand, too many of these conflicting uses may create a tipping point at which land conversion accelerates once farmland drops below critical mass. It is uncertain what qualifies as "too many" conflicting uses or the exact critical mass threshold. What is certain is that these phenomena occur at a spatially precise scale; measuring them in turn, require spatially precise data. I attempted to bridge methodological gaps by providing an extensive look at non-farm activity using parcel level data. Based on my cleaned results, roughly $5 \%$ to $8 \%$ of tax lots that fall within the EFU zone filed for a non-farm or distinct permit during the 1993-2015 period. The data quality and large time frame limited my ability to properly engage theories regarding the negative and positive impacts of non-farm activity on agricultural lands. However, this study has produced empirical evidence where non-farm activity has clustered, laying the groundwork for more intensive research in the future to provide narratives for the data. Specifically, the results reveal some interesting findings that may provide researchers direction. 
First, data summarized at the County level, such as the number of non-farm cases, did not indicate with how spatially clustered or dispersed data were. For example, Clackamas County contained $12 \%$ of all dwellings, but no statistically significant clusters were detected. Conversely, Polk County contained just 19\% of dwelling cases, but 40\% of all dwellings that fell within a hotspot. Future research should use caution when making assumptions about micro-level interactions using larger level data because data aggregated at the county level cannot appropriately address trends at sub-county levels. Second, I recommend a follow up for a few identified hotspots. These include non-farm use clusters in Marion County (Figure 11), which contain a number of home occupations and commercial activities, and dwelling group 1 near the Yamhill/Polk boundary (Figure 7), which is fairly isolated from urban centers. I recommend a site visit in the future to ascertain why so many permits have been located out in these areas and the impacts on farmland, if any, that have occurred. Third, viticulture and agri-tourism cases tended to group together with other non-farm uses, particularly within "use” groups 1 and 3. With more information, it would be interesting to see if these activities developed in conjunction with other uses, precluded them, or vice versa. Lastly, there were a variety of methodological challenges I'd like to address and offer suggestions to how that data could be better maintained and utilized. 


\section{Section VI. Limitations and Future Research}

The nature of permit data limited our ability to track cases that have occurred illegally, or those that did not go through the formal permit approval process. I understand that the data does not paint a full picture of non-farm activity the Northern Willamette Valley, but that limitation is also an asset. It is probable the extent of these phenomena are much more pervasive in reality than what I am able to show, which emphasizes the need for more resources and research to track them. Another feature worth pursuing, one that this study did not examine, is the relationship between land quality and the prevalence of non-farm activity. In theory, non-farm uses and dwellings should be allocated towards lands with lower soil quality and/or other physical barriers to farming, but I did not test the validity of this statement. Concomitantly, including the soil quality of a permit's parcel would make the aforementioned task easier to accomplish. This study mentioned other limitations regarding the quality of the data in previous sections, but I've summarized them in the following sections.

Some permit descriptions were too vague for me to re-classify properly. A case in point are dwelling replacements which did not state the type of building being replaced or built. While DLCD keeps track of how previous dwellings are “replaced,” either through removal, demolition, or conversion, this information was not available in the permit approval dataset (DLCD, 2017). Including the method of replacement and the type of residences that are being demolished or built would improve one's ability to interrogate the data. There are of course other cases, such as temporary hardships, that could be better tracked, but improving the dwelling replacement data should take precedence because they makes up the majority of dwelling cases and contain least amount of clarity. 
Relatedly, I excluded 194 geocoded uses from my analysis because there was not enough information to indicate a specific use. The majority of these observations were "variance" and "floodplain development" cases that did not clarify if a development or operation had been approved, let alone a description of the activity. As is the case with dwelling replacements, it seems likely that this information would be on the original permit if it was approved. Including these minor additions would go a long way to improving data transparency and increasing the datasets sample size to allow for more robust analyses.

Data standardization is another related matter that should be pursued. Inconsistent classifications were less of an issue for dwellings, which only contained 7 residence types, but occurred more frequently within the use dataset. This study attempted to standardize cases into relationship groups (Non-farm, Distinct, Farm Related), but more systematic efforts from counties or DLCD to normalize data collection would make this data easier to track and more comparable across the state. For one, the term "non-farm" needs to be operationalized more clearly in the Oregon Revised Statutes (ORS). This study did not deeply engage on what qualifies as "non-farm” beyond their potential impacts on farming, but I recommend this be done by the state rather than the researcher's discretion. Some uses, such as golf courses and schools, are clearly not farm related, but others, such as processing facilities, seem beneficial, if not pivotal, to farming practices. Removing farm related operations would improve the quality and validity of the dataset. Another suggestion is for DLCD and the counties to standardize subcategories in a way that they can be distinguished from one another. Commercial activities, home occupations, and other uses seemed to blend together in that their specific uses could have classified under any one of them. Relatedly, it would be helpful 
if there was information that measured the extent of a non-farm operation. Specifically, how much of a parcel's area is required for a particular use? These changes would help researchers' ability to qualify non-farm operations' relative impacts on farming based on their nature and size.

Finally, I was unable to geocode roughly 1800 cases, about one-third of the data, nearly all of which were missing a tax lot ID. Since each permit is filed through counties, it is possible that some counties track the street address more rigorously than the parcel number. However, it is unlikely that a permit could be approved without including its respective parcel number or address, so a follow up with the counties or DLCD is warranted. Regardless, I suggest the street address, assuming it is collected, be included in the dataset to cross reference the tax lot ID or provide supplementary information for one to geocode. For this study, the large number of unplotted cases excluded from the analysis compelled me to examine the "unknown" cases more thoroughly.

I ran descriptive statistics to determine the relationship between the unknown cases and the matched cases. If the unknown cases are "missing not at random" (MNAR), that indicates an association between the missing values and observed values, which produces biased results (Donders, van der Heijden, Stijnen, \& Moons, 2006; Schafer \& Graham, 2002). For example, if our study determined Clackamas County did not contain any statistically significant clusters of non-farm activity, but $80 \%$ of unknown cases were from the county, one would not be able to discern whether these results were influenced by the unknown cases. For this study, I determined whether missing tax lot data were associated with an activity or county. With the exception of Multnomah County, which contained the fewest amount of permits, the percent of unknown cases roughly ranged 
between 30\%-40\% (Table 12). Marion County contained the plurality of unknown cases and the highest proportion of unknown cases, but overall was in line with the other counties. Unknown cases by dwelling types also ranged from 30\% to 40\% with primary farm dwellings being the highest in relative terms and dwelling replacements in absolute terms (Table 13).

Table 12: Unknown Cases by County

\begin{tabular}{|l|c|c|}
\hline \multicolumn{1}{|c|}{ County } & Unknown & Unknown\% \\
\hline Clackamas & 150 & $29 \%$ \\
Marion & 709 & $41 \%$ \\
Multnomah & 16 & $14 \%$ \\
Polk & 312 & $36 \%$ \\
Washington & 346 & $29 \%$ \\
Yamhill & 241 & $32 \%$ \\
\hline
\end{tabular}

Table 13: Unknown Dwellings by Type

\begin{tabular}{|l|c|c|}
\hline \multicolumn{1}{|c|}{ Dwelling Type } & Unknown & Unknown\% \\
\hline Accessory Farm Worker Housing & 76 & $39 \%$ \\
Dwelling Replacement & 492 & $30 \%$ \\
Lot Of Record & 100 & $31 \%$ \\
Non Farm Dwellings & 99 & $39 \%$ \\
Primary Farm Dwelling & 131 & $40 \%$ \\
Relative Farm Assistance & 73 & $37 \%$ \\
Temporary Hardship & 275 & $34 \%$ \\
\hline
\end{tabular}

Unknown farm use cases varied much more so than dwellings, with the plurality of cases occurring in the "other" sub category (Table 14). ${ }^{2}$ Due to small sample sizes, the percentage of unknown cases was inflated for half of the subcategories, though Accessory Uses, Mining/ Aggregate (Min/Agg.), and Public Facilities, had relatively high unknown percentages that were unaffected by their sample sizes.

\footnotetext{
${ }^{2}$ The full list of unknown uses by subcategory can be found in Appendix A
} 
Table 14: Unknown Uses by Subcategory

\begin{tabular}{|l|c|c|}
\hline \multicolumn{1}{|c|}{ Subcategory Use* } & Unknown & Unknown $\%$ \\
\hline Other & 65 & $38 \%$ \\
Utility Facility & 55 & $35 \%$ \\
Home Occupation & 45 & $23 \%$ \\
Accessory Use & 42 & $48 \%$ \\
Comm. Act. & 37 & $39 \%$ \\
Road & 33 & $63 \%$ \\
Variance & 26 & $67 \%$ \\
Min/Agg. & 22 & $61 \%$ \\
Residence & 16 & $42 \%$ \\
Temporary Use & 13 & $41 \%$ \\
Winery & 13 & $22 \%$ \\
Agricultural building & 12 & $32 \%$ \\
Public Facility & 12 & $63 \%$ \\
Farm Stand & 11 & $27 \%$ \\
Church & 9 & $41 \%$ \\
Nonconforming use & 9 & $45 \%$ \\
Roads and Improvements & 9 & $82 \%$ \\
Conditional Use & 8 & $80 \%$ \\
Special Use & 8 & $33 \%$ \\
Other Use & 6 & $22 \%$ \\
\hline
\end{tabular}

*For the full list of unknown cases by subcateogry see appendix $A$

In summary, no particular county, excluding Multnomah County, was more or less likely to have missing cases, though Marion County had the poorest data quality in terms of its proportion of unknown cases (41\%). Relatedly, Marion County also contained the majority (59\%) of imprecise cases that were geocoded to the PLSS area (Appendix B). Unknown cases varied little amongst dwelling types, but varied more for non-farm uses. Overall, unknown cases appear to be randomly distributed, though it is possible our study is missing hotspot areas. If we think of the missing cases as a subset of the entire dataset, it would be reasonable to assume the missing permits would be spatially clustered in similar intensities as the geocoded permits. I can only speculate whether permits with missing locations are clustered near the same hot spots I've identified or in completely new areas unbeknownst to us. While the missing data 
impacted our ability to perform more statistically rigid analyses, their influence was more or less innocuous for what I tried to achieve: identifying hotspots for future research. 


\section{Section VII. Conclusion}

Since the passage of Senate Bill 100 in 1973, Oregon has focused collective efforts toward balancing development pressures for growth and conserving the state's finite inventory of farmland. EFU zones act as a barriers to safeguard Oregon’s farmland from other conflicting uses, but they are becoming increasingly porous. Between 1993 and 2015, permitted non-farm uses and dwellings have proliferated both in activity and, for the former, the number of allowed uses, but the consequences of their expansions are still unclear. On the one hand, the corporatization and globalization of the food industry has put the onus on farms to find new means to compete. In this regard, non-farm uses and, to a lesser degree, dwellings provide supplementary income for farm operations to push back against global processes. Even so, these are only temporary, and potentially destructive, solutions to a much deeper problem that remains unaddressed: the devaluation of farming as an economically sustainable form of production. While these activities may be beneficial for individuals, concerns lie in the cumulative, long term impacts these activities may have on the agricultural industry as a whole. We must be proactive, not reactive, in studying these phenomena to determine if its impacts are more innocuous or detrimental to farmlands.

The findings I've presented are perhaps the most conservative scenario of what is occurring in the NWV and much more work is needed to fully measure the full extent of this process. I recognize that researching these occurrences is no small task, but if the state is seriously concerned about conflicting uses cascading throughout "protected" agricultural lands, more resources need to be devoted to track and maintain this data. As Oregon continues to grow and the economic viability of farming continues to decline, 
there will be added pressure from farm owners, speculators, and government agencies alike to unhinge the statewide land use system that Oregon prides itself on. 


\section{References}

Adelaja, A., Sullivan, K., \& Hailu, Y. G. (2011). Endogenizing the Planning Horizon in Urban fringe agriculture. Land Use Policy, 28(1), 66-75. https://doi.org/10.1016/j.landusepol.2010.05.002

Anselin, L. (1995). Local indicators of spatial association-LISA. Geographical Analysis, 27(2), 93-115.

Ayazi, H., \& Elsadig, E. (2015). The US Farm Bill: Corporate Power and Structural Racialization in the United States Food System. Haas Institute for a Fair and Inclusive Society.

Berry, D., \& Plaut, T. (1978). Retaining agricultural activities under urban pressures: a review of land use conflicts and policies. Policy Sciences, 9(2), 153-178.

Brookfield, H. (2008). Family Farms Are Still Around: Time to Invert the Old Agrarian Question. Geography Compass, 2(1), 108-126. https://doi.org/10.1111/j.17498198.2007.00078.x

Bryant, C. R., \& Russwurm, L. H. (1979). The impact of non-farm development on agriculture: a synthesis. Plan Canada, 19(2), 122-139.

Busby, G., \& Rendle, S. (2000). The transition from tourism on farms to farm tourism. Tourism Management, 21(6), 635-642. https://doi.org/10.1016/S02615177(00)00011-X

Condon, P. M., Mullinix, K., Fallick, A., \& Harcourt, M. (2010). Agriculture on the edge: strategies to abate urban encroachment onto agricultural lands by promoting viable human-scale agriculture as an integral element of urbanization. 
International Journal of Agricultural Sustainability, 8(1), 104-115.

https://doi.org/10.3763/ijas.2009.0465

DLCD. (2010). Goal 3: Agricultural Lands. Retrieved from https://www.oregon.gov/LCD/docs/goals/compilation_of_statewide_planning_go als.pdf

DLCD. (2012). Guide to Wineries and Events in EFU Zones. Retrieved from http://www.oregon.gov/LCD/docs/rulemaking/201113/guide_ winerieseventsinefuzones_2012.pdf.

DLCD. (2017). 2014-2015 Oregon Farm \& Forest Report.

Donders, A. R. T., van der Heijden, G. J. M. G., Stijnen, T., \& Moons, K. G. M. (2006). Review: A gentle introduction to imputation of missing values. Journal of Clinical Epidemiology, 59(10), 1087-1091. https://doi.org/10.1016/j.jclinepi.2006.01.014

ESRI. (2017). What is geocoding? Retrieved from http://pro.arcgis.com/en/proapp/help/data/geocoding/what-is-geocoding-.htm

Flegg, A. T., Webber, C. D., \& Elliott, M. V. (1995). On the Appropriate Use of Location Quotients in Generating Regional Input-Output Tables. Regional Studies, 29(6), 547-561. https://doi.org/10.1080/00343409512331349173

Friedmann, H. (1982). The political economy of food: the rise and fall of the postwar international food order. American Journal of Sociology, 88, S248-S286.

Fuller, A. M. (1990). From part-time farming to pluriactivity: a decade of change in rural Europe. Journal of Rural Studies, 6(4), 361-373. 
Haugen, M. S., \& Vik, J. (2008). Farmers as entrepreneurs: the case of farm-based tourism. International Journal of Entrepreneurship and Small Business, 6(3), 321. https://doi.org/10.1504/IJESB.2008.019130

Hendrickson, M., Heffernan, W. D., Howard, P. H., \& Heffernan, J. B. (2001). Consolidation in food retailing and dairy. British Food Journal, 103(10), 715-728. https://doi.org/10.1108/00070700110696742

Howard, P. (2016). Concentration and Power in the Food System: Who Controls What We Eat? New York, NY: Bloomsbury Academic.

Kautsky, K. (1988). The agrarian question: in two volumes. London; Winchester, Mass: Zwan Publications.

Kline, J. D. (2005). Forest and Farmland Conservation Effects of Oregon's (USA) LandUse Planning Program. Environmental Management, 35(4), 368-380. https://doi.org/10.1007/s00267-004-0054-5

Kline, J. D., \& Alig, R. J. (1999). Does land use planning slow the conversion of forest and farmlands? Growth and Change, 30(1), 3-22.

Lang, T. (2003). Food industrialisation and food power: implications for food governance. Development Policy Review, 21(5-6), 555-568.

Lehman, R. (2015). Conflicts in Resource Zones. OAPA.

Lockeretz, W., Freedgood, J., \& Coon, K. (1987). Farmers Views of the prospects for agriculture in a metropolitan area.pdf. Agricultural Systems, 87, 43-61.

Lynch, L. (2006). Economics and Contemporary Land Use Policy: Development and Conservation at the Rural-Urban Fringe. Routledge. Retrieved from http://www.tandfebooks.com/isbn/9781936331659 
Lynch, L., \& Carpenter, J. (2003). Is there evidence of a critical mass in the Mid-Atlantic agriculture sector between 1949 and 1997? Agricultural and Resource Economics Review, 32(1), 116-128.

MacPherson, H., \& Hallock, T. Senate Bill 100 (1973).

Mann, S. (1990). Agrarian Capitalism: In Theory and Practice. Chapel Hill: North Carolina Press.

Mann, S., \& Dickinson, J. (1978). Obstacles to the development of a capitalist agriculture. The Journal of Peasant Studies, 5(4), 466-481. https://doi.org/10.1080/03066157808438058

McMichael, P. (2009). A food regime analysis of the "world food crisis." Agriculture and Human Values, 26(4), 281-295. https://doi.org/10.1007/s10460-009-9218-5

McMichael, P. (2013). Food Regimes and Agrarian Questions. Rugby, Warwickshire, United Kingdom: Practical Action Publishing. Retrieved from http://www.developmentbookshelf.com/doi/book/10.3362/9781780448794

Miller, M. M., \& Gibson, L. J. (1991). Location quotient: A basic tool for economic development... Economic Development Review, 9(2), 65.

Nelson, A. C. (1992). Preserving Prime Farmland in the Face of Urbanization: Lessons from Oregon. Journal of the American Planning Association, 58(4), 467-488. https://doi.org/10.1080/01944369208975830

Oregon Revised Statutes. Legislative Findings related to non-farm dwellings, ORS § 215.262 (2015).

Oregon Revised Statutes. Uses permitted in exclusive farm use zones in counties that adopted marginal lands system prior to 1993; rules, ORS § 215.213 (2015). 
Rose, J. G. (1984). Farmland preservation policy and programs. Nat. Resources J., 24, 591.

Schafer, J. L., \& Graham, J. W. (2002). Missing data: Our view of the state of the art. Psychological Methods, 7(2), 147-177. https://doi.org/10.1037//1082989X.7.2.147

Searle, B. (2012). A Comprehensive Valuation of Agricultural Lands: A Perpetual Investment in Oregon’s Economy and Environment. Oregon Department of Agriculture.

Tulloch, D. L., Myers, J. R., Hasse, J. E., Parks, P. J., \& Lathrop, R. G. (2003). Integrating GIS into farmland preservation policy and decision making. Landscape and Urban Planning, 63(1), 33-48.

United States Census Bureau’s Population Estimates Program. (2015). Population and Housing Unit Estimates. Retrieved from https://www.census.gov/programssurveys/popest.html

Wang, Q., \& Pandit, K. (2007). Measuring Ethnic Labour Market Concentration and Segmentation. Journal of Ethnic and Migration Studies, 33(8), 1227-1252. https://doi.org/10.1080/13691830701614023

Wong, W. (2009). The Modifiable Areal Unit Problem (MAUP). In The SAGE Handbook of Spatial Analysis (pp. 105-123). SAGE Publications.

Wu, J., Fisher, M., \& Pascual, U. (2011). Urbanization and the viability of local agricultural economies. Land Economics, 87(1), 109-125. 
Zollinger, B., \& Krannich, R. S. (2002). Factors Influencing Farmers’ Expectations to Sell Agricultural Land for Non-Agricultural Uses*. Rural Sociology, 67(3), 442463. 


\section{Appendix A: Additional Tables}

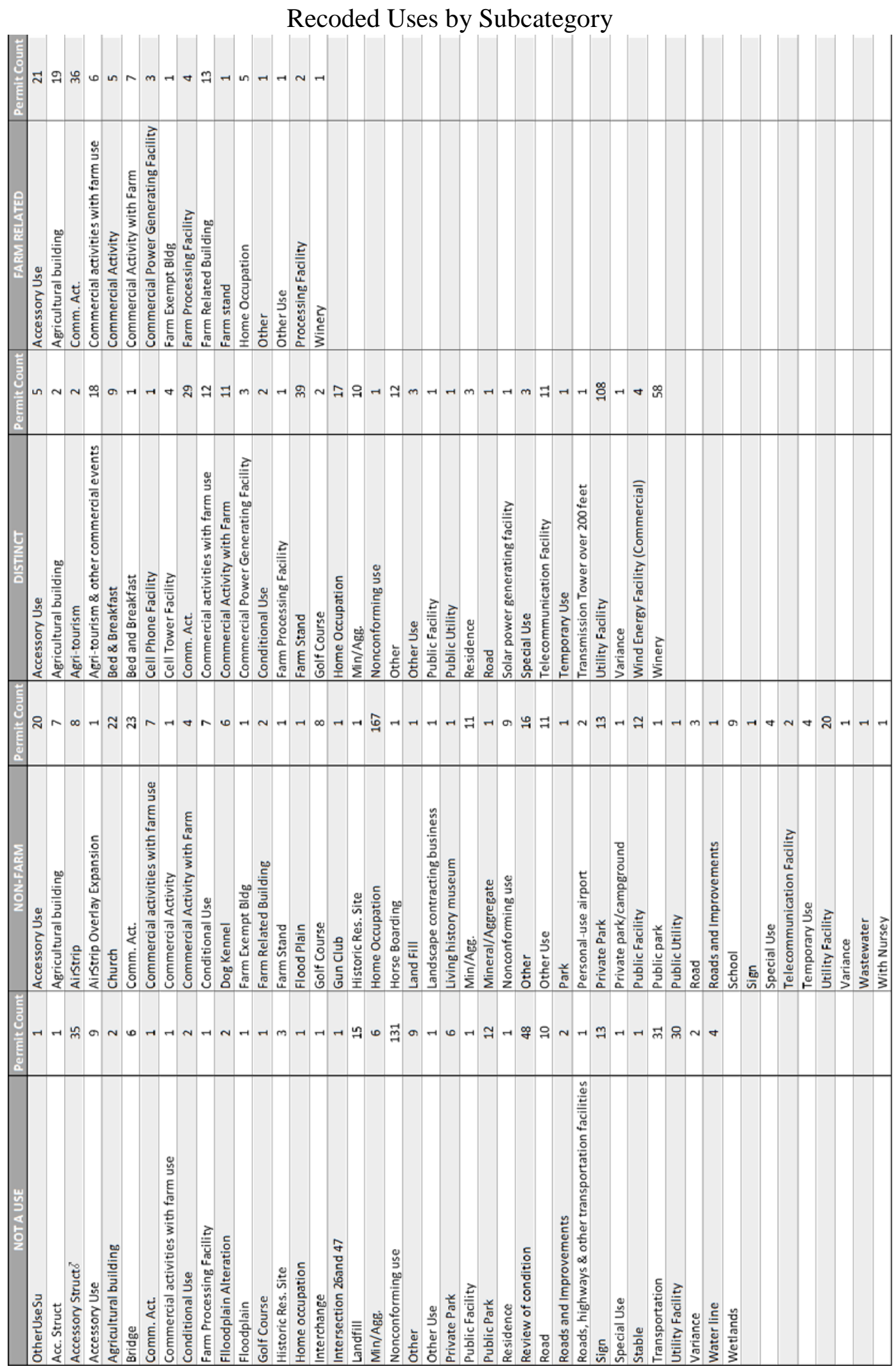




\section{Appendix A: Additional Tables (Cont.)}

All Unknown Uses by Subcategory

ㅎํㄴ

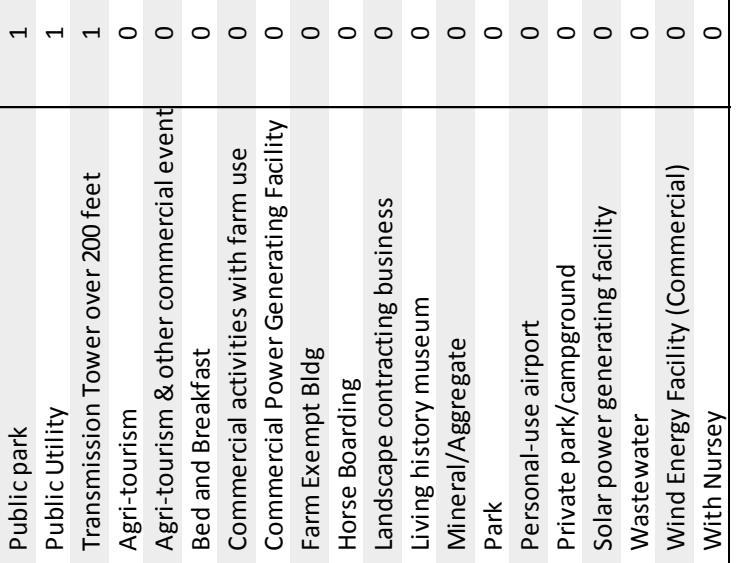

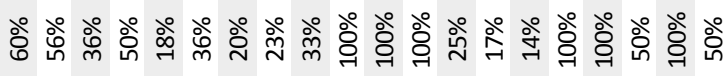

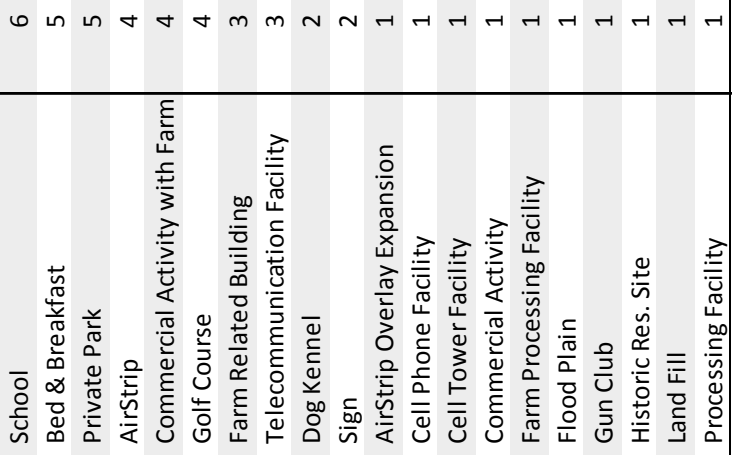

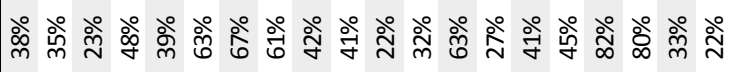

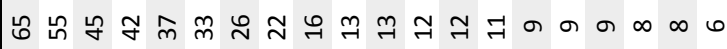

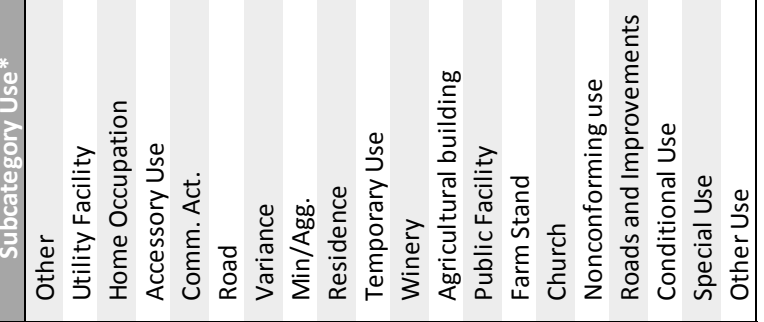


Appendix A: Additional Tables (Cont.)

Uses (Distinct \& Non-Farm) Within Hotspots

\begin{tabular}{|c|c|c|c|}
\hline SubCategory & Within Cluster & Total & Percent \\
\hline Accessory Use & 4 & 18 & $22 \%$ \\
\hline Agricultural building & 1 & 8 & $13 \%$ \\
\hline $\begin{array}{l}\text { Agri-tourism \& } \\
\text { other commercial } \\
\text { events }\end{array}$ & 7 & 17 & $41 \%$ \\
\hline AirStrip & 1 & 4 & $25 \%$ \\
\hline Bed \& Breakfast & 3 & 4 & $75 \%$ \\
\hline Bed and Breakfast & 1 & 1 & $100 \%$ \\
\hline Cell Tower Facility & 1 & 3 & $33 \%$ \\
\hline Church & 6 & 13 & $46 \%$ \\
\hline Comm. Act. & 15 & 30 & $50 \%$ \\
\hline $\begin{array}{l}\text { Commercial } \\
\text { activities with farm } \\
\text { use }\end{array}$ & 6 & 19 & $32 \%$ \\
\hline $\begin{array}{l}\text { Commercial Activity } \\
\text { with Farm }\end{array}$ & 8 & 12 & $67 \%$ \\
\hline Conditional Use & 1 & 2 & $50 \%$ \\
\hline Dog Kennel & 1 & 4 & $25 \%$ \\
\hline Farm Exempt Bldg & 1 & 1 & $100 \%$ \\
\hline $\begin{array}{l}\text { Farm Related } \\
\text { Building }\end{array}$ & 1 & 1 & $100 \%$ \\
\hline Farm Stand & 8 & 29 & $28 \%$ \\
\hline Golf Course & 1 & 4 & $25 \%$ \\
\hline Home Occupation & 27 & 139 & $19 \%$ \\
\hline Min/Agg. & 3 & 7 & $43 \%$ \\
\hline Mineral/Aggregate & 1 & 1 & $100 \%$ \\
\hline Other & 2 & 18 & $11 \%$ \\
\hline Other Use & 3 & 11 & $27 \%$ \\
\hline Personal-use airport & 1 & 2 & $50 \%$ \\
\hline Public Facility & 3 & 6 & $50 \%$ \\
\hline Public Utility & 1 & 1 & $100 \%$ \\
\hline School & 2 & 3 & $67 \%$ \\
\hline Special Use & 1 & 3 & $33 \%$ \\
\hline $\begin{array}{l}\text { Telecommunication } \\
\text { Facility }\end{array}$ & 2 & 7 & $29 \%$ \\
\hline Utility Facility & 6 & 85 & $7 \%$ \\
\hline $\begin{array}{l}\text { Wind Energy Facility } \\
\text { (Commercial) }\end{array}$ & 1 & 4 & $25 \%$ \\
\hline Winery & 21 & 44 & $48 \%$ \\
\hline \multicolumn{3}{|c|}{$\%$ of total cases within cluster } & $\underline{26 \%}$ \\
\hline \multicolumn{4}{|c|}{$\begin{array}{l}\text { Bold S ubcat ego ries fall under Commeric al activity \& ho me occ upation, A gri-tounism \& Wineries, o } \\
\text { Utility \& Energy Facilities }\end{array}$} \\
\hline
\end{tabular}




\section{Appendix B: Additional Figures}

Sensitivity of LISA results ( $(1 / 2$ mile, $3 / 4$ mile, 1 mile)
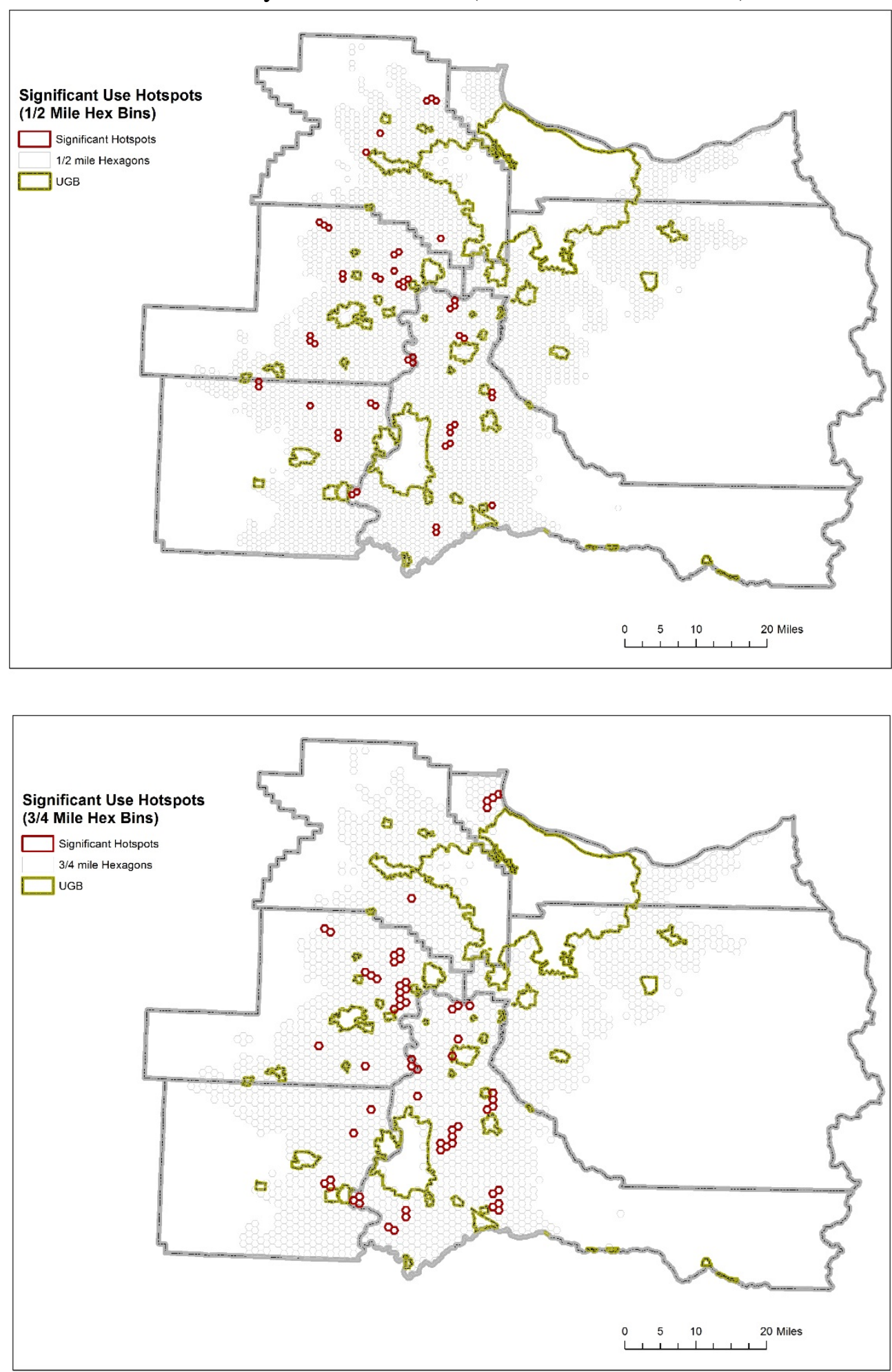
Appendix B: Additional Figures (Cont.)

Sensitivity of LISA results (1/2 mile, 3/4 mile, 1 mile) (Cont.)

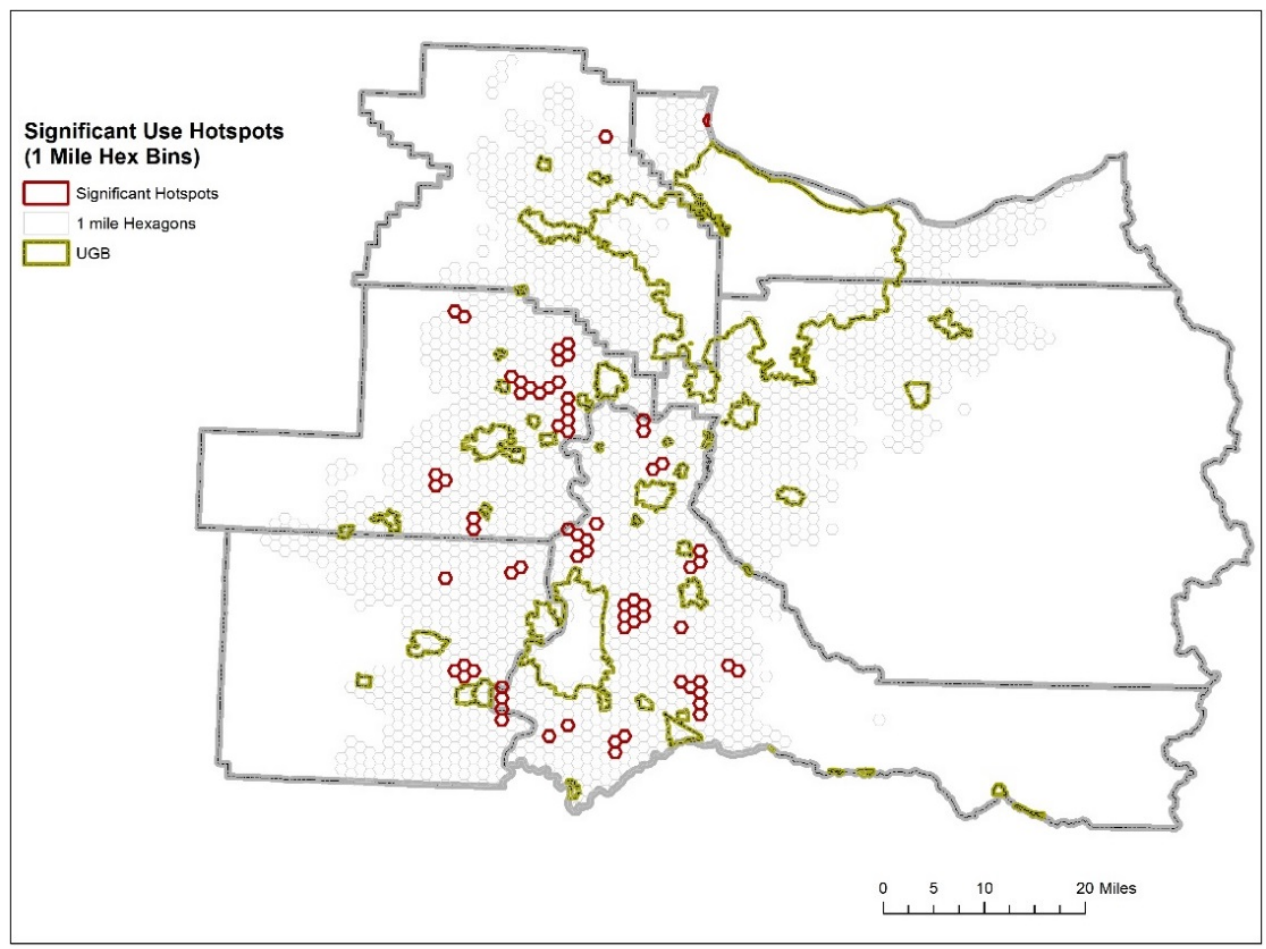

Geocoded Permits by PLSS or Tax Lot Match

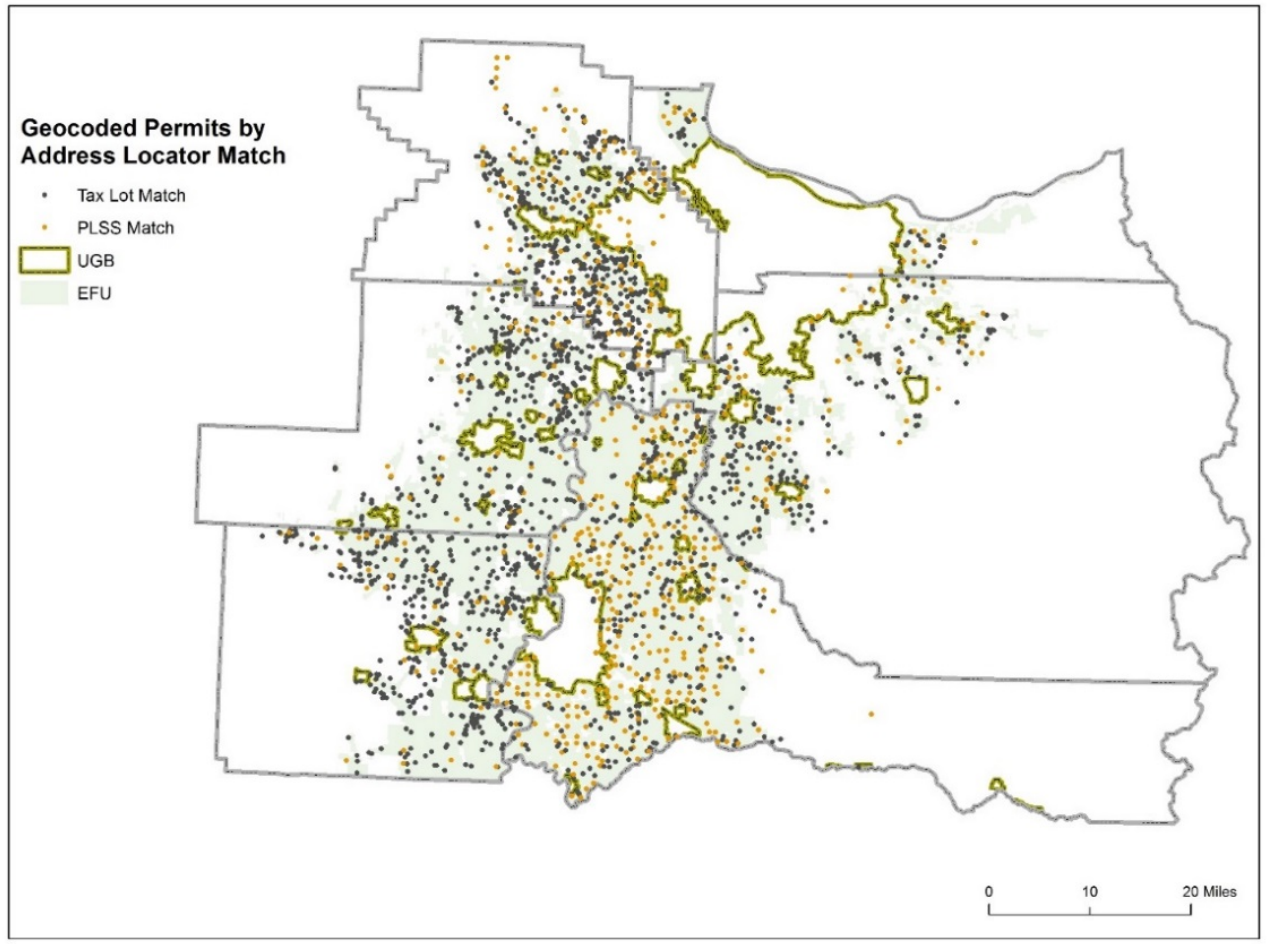


Appendix B: Additional Figures (Cont.)

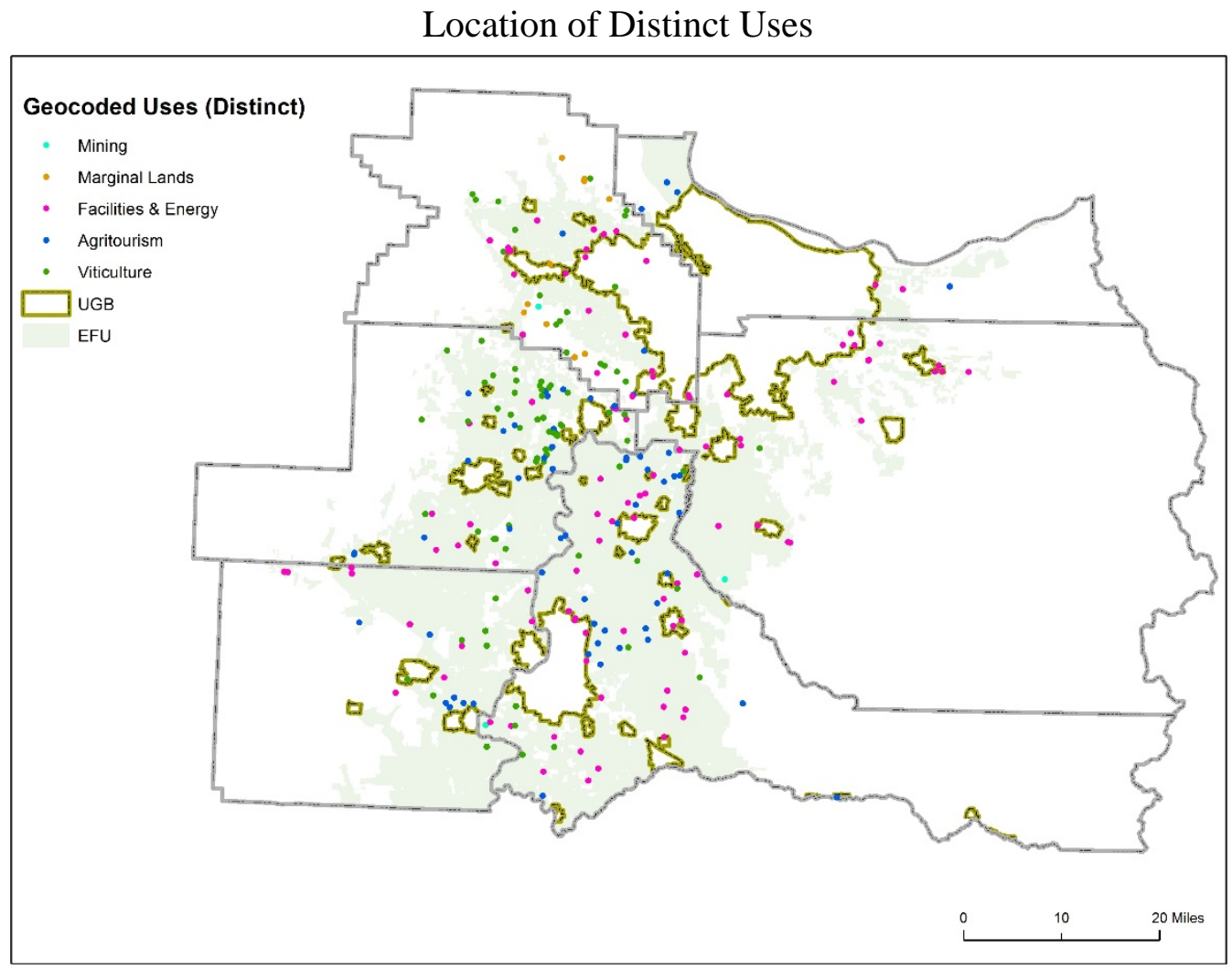




\section{Appendix C: Detailed Methodology}

\section{GEOCODING POINTS USING TL ID}

FarmOtherUse: Original Geocode: 518 out of 896 possible matches (515 with no TL ID, can't match)

Corrected 13 Tied cases, Dir Characters were removed in the TL ID standardization process, but the correct location was surmised by overlaying the PLSS layer and matching the correct location that corresponded with the permits' Township and Range Characters.

FarmOtherUse_PLSS: Geocode missing cases based on a truncated TL ID (356 out of 378 possible cases), Location within a square mile.

FarmOther_Final: Merged PLSS and Original Files (1411 cases, 874 out of 896 possible matches, 537 with no match; 38\% unknown)

356 cases using PLSS locator (40.7\% of matches) and 518 cases using TL locator(59.2\% of matches).

FarmDwelling: 1616 out of 2501; 1263 with no TL ID Information

Corrected 55 Tied cases, Dir Characters were removed in the TL ID standardization process, but the correct location was surmised by overlaying the PLSS layer and matching the correct location that corresponded with the permits' Township and Range Characters.

FarmDwelling_PLSS: 798 out of 885 possible matches;

87 missing; Most likely input errors though I'm not completely sure so I didn't make the corrections. Most of the missing is in Yamhill County with Township and Range characters of N and W, respectively. Given that the entire county (yamhill) is in the SW, its safe to say that these TL's don't exist.

FarmDwelling_Final: Merged PLSS and Original Files (3764 cases; 2418 out of 2501 possible matches, 1346 unmatched; 35.7\% unknown). Manually matched (Type PP) 4 cases up to section bringing the total from 2414 to 2148

1654 cases using the TL locator (68\%) and 764 cases using PLSS locator (32\%)

Found 40 cases(all matched or tied, reliability 99) with multiple Taxlots that the substring code didn't catch. 38 out of 40 cases perfectly matched (reliability =1) after correcting TL_ID. 
Total Farm Other Use and Dwelling combined: 5175 total cases; 3397 possible matches and 1778 with unmatched; 34.3\% unknown. 3292 out of 3397 possible matches; 96.9\%.

Analyzing Intersections: Determine which intersections are legitimate and which are duplicates.

Intersect $=1$ indicates that the case self-intersects with another point within its own layer (Two Dwelling approvals for the same taxlot).

Intersect $=2$ indicates that the case intersects with another point from the other layer (Home occupation approval on the same taxlot as a Dwelling approval).

Intersect $=3$ indicates that the case both intersects with points within and between layers. (Two Dwelling approvals and an approved home occupation on the same taxlot).

Removal $=1$ indicates that there is a Intersect of the same year, type, and ID within its own layer that will be removed from analyses, but remain in the dataset.

Removal $=2$ indicates that there is a Intersect case of the same year, type, and ID between layers that will be removed from the analyses, but remain in the dataset.

FarmOtherUse_Final_SelfIntersect: Select out autointersected cases. (95 cases-43 unique- out of 874 matches).

Brought FarmOther_Duplicate(Text file) into Access to remove superfluous cases (Intersect $=1$ )

Cases with identical TLID, Year, Specific Use were flagged (Remove=1; 15 out of 95 cases)

FarmDwelling_Final_SelfIntersect: Select out autointersected cases. (277 cases-131 unique- out of 2418 matches).

Brought FarmDwelling_Duplicate(Text file) into Access to remove superfluous cases (Intersect $=1$ )

Cases with identical TLID, Decision Date, Type of Dwelling, and Parcel size were flagged (Remove $=1,29$ out of 277 cases flagged as superfluous duplicates)

$\underline{\text { Intersect Farm Dwelling and Farm Other Use points, to find duplicate dwelling permits }}$

Intersect returned 375 cases( Intersect $=2$ or 3). Selection query where 
FarmOther_Final.Year $=$ FarmDwelling_Final.Year AND

FarmOther_Final.TL_ID_FarmOther $=$ FarmDwelling_Final.TL_New_ID

Returned 11 out 375 cases where taxlot ID and the year matched.

(Remove $=2,1$ out of 11 cases was flagged as a duplicate where both uses were a lot of record)

1140 out of 3292 matched cases intersect, or fall on top of, another point. 45 duplicates (out of 1140 Intersects) that are flagged and will not be included in analyses (though will remain in the set).

635 Self Intersections (55.7\%, Intersect =1)

238 Between-Intersections (20.9\%, Intersect=2)

267 Inter and Intra Intersections ( $23.4 \%$, Intersect $=3$ )

\section{After selecting out 45 duplicates...}

Total Farm Other Use and Dwelling combined: 5130 total cases; 3352 possible matches and 1778 with unmatched; $34.7 \%$ unknown.

3247 out of 3352 possible matches; 96.9\%.

\section{RECLASSIFYING DIFFERENT TYPES OF USES AND DWELLING}

Brought FarmOther_Final_ForReclassification (Text File) Into Access to code non-farm uses into

Recode $=-1$; Case is not really a an approval for a specific use (Reviews, Floodplain, etc)- 194 cases; New total of $\mathbf{6 8 0}$ matched cases of non-farm activity

Recode = 2; Uses facilitate farm production - 87 Cases, $13 \%$

Recode $=1$; Impact on farm use is unknown (Agritourism, Viticulture, etc) -281 cases, $41 \%$

Recode $=0$; Use with no relation to farming- 267 cases, 39\%

Recode = 999; Case refers to a Dwelling Unit, not a use -45 cases, $7 \%$

Brought FarmDwelling_Final_ForReclassification (Text File) Into Access to Code nonfarm dwellings from farm dwellings. 
Recode $=-1$; Case has no description of the Dwelling type -10 cases; New total of 2408 matched cases of Permitted Dwelling Activity

Recode $=2$; Dwelling for Farming (Acc. Farm Worker Housing \& Primary Farm

Dwelling) - 310 Cases, 13\%

Recode $=1$; Dwelling may or may not be associated with farming and status of the dwelling unit is not tracked

Dwelling replacement- 1114 cases, $46 \%$

Relative Farm Assistance \& Temporary Hardship- 631 cases, 26\%

Recode = 0; No relation to farming (Lot of Record \& Non-Farm Dwelling)- 353, $15 \%$

\section{Merging other use cases that were dwellings (Recode $=999)$ with}

\section{Farm_Dwelling_Final}

Moved 95 cases from other use to Dwelling layer. Cases that were too vague on the type of residence were subsumed under Dwelling Replacement.

Recode = 2; Dwelling for Farming (Acc. Farm Worker Housing \& Primary Farm Dwelling) - 3 Cases, 3\%

Recode $=1$; Dwelling may or may not be associated with farming and status of the dwelling unit is not tracked

Dwelling replacement- 25 cases, 26\%

Relative Farm Assistance \& Temporary Hardship- 38 cases, 40\%

Recode = 0; No relation to farming (Lot of Record \& Non-Farm Dwelling)- 29, $30 \%$

FarmOther_Final_Cleaned: Cleaned dataset that includes cases that are only "uses"

1316 total cases; 848 possible matches (64\%) and 468 unknown cases (36\%)

829 matches out of 848 possibilities (98\%)

FarmOther_Final_Selection: 624 out of 829 cases (75\%) that are not superfluous (remove=null) and a "use" (recode $<>-1$ )

388 cases using TL locator (62\%) \& 236 cases using PLSS locator (38\%)

538 cases that were not explicitly farm related (recode $<>2$ ). 
FarmDwelling_Final_Cleaned: Cleaned dataset that includes cases that are only Dwellings

3859 total cases; 2549 possible matches (66\%) and 1309 unknown cases (34\%) 2463 matches out of 2549 possible matches (97\%)

FarmDwelling_Final_Selection: 2430 out of 2463 matches (99\%) that are not superfluous (remove $=$ null or remove $=99$ )

1655 cases using TL locator (68\%) \& 775 cases using PLSS locator (32\%)

2126 cases that were not explicitly farm related (recode $<>2$ ).

Total Farm Other Use and Dwelling combined: 5175 total cases; 3397 possible matches and 1778 with unmatched; 34.3\% unknown. 3292 out of 3397 possible matches; 96.9\%.

Total_Final_Selection: 3054 out of 3292 cases (93\%) that are not superfluous 2664 cases that were not explicitly farm related (recode $<>2$ )

Tranforming Tl Locator points (reliability $=1$ ) into the respective taxlot polygon layers. Used the most recent recode for taxlots with multiple permits.

FarmOther_Poly_Final: Aggregate 477 Other cases to the TL polygons for a total of 437 unique polygons; 357 polygons that are actual “uses” (Recode_Recent $<>-1$ )

29 taxlots contained multiple permits

FarmDwelling_Poly_Final: Aggregate 1655 Dwelling cases to the TL polygons for a total of 1530 unique polygons.

112 taxlots contained multiple permits

Total Farm Other Use and Dwelling Polygons combined: 1887 total cases; 141 taxlots with multiple permits

(1)Estimating the area of PLSS points (reliability= 99,9) by analyzing the taxlots within each PLSS boundary. (2) Analyzing the area/size distribution of PLSS boundaries to inform bandwith size of the hexagonal polygons the points will be aggregated to.

PLSS _FarmOther_Final: 191 cases that contained a PLSS Use point. Based on the taxlots within each PLSS boundary the min, max, mean, and median acreage was 
calculated to produce a range of possibilities the TL area could be. 6 out of 191 cases could not derive taxlot statistics because no centroids fell within its boundary.

Areas for the PLSS boundaries that contained a PLSS Use point varied from .01 to 1.09 sq miles. The mean area is .65 sq miles, median is .74, and SD of .36.

PLSS_FarmDwelling_Final: 533 cases that contained a PLSS Dwelling point. Based on the taxlots within each PLSS boundary the min, max, mean, and median acreage was calculated to produce a range of possibilities the TL area could be. 16 out of 533 cases could not derive taxlot statistics because no centroids fell within its boundary.

Areas for the PLSS boundaries that contained a PLSS Dwelling point varied from .001 to 1.6 sq miles. The mean area is .67 sq miles, median is .78, and SD of .35.

Creating hex bins of 3 different sizes (1/2 mile, $3 / 4$ mile, and 1 mile) to aggregate data to and test the sensitivity of the LQ and LISA tests.

Creating MEDIUM hex bins for aggregating the points and TLs. Hex bins were clipped to the county boundary.

7602 total hexes within the 6 counties, 3030 hexes (Hex_EFU) that intersect with EFU zone boundary or contain a use/dwelling point.

Hex area is roughly $3 / 4$ of a square mile in line with the median area of the PLSS boundaries that contain a dwelling or use.

Creating LARGE hex bins for aggregating the points and TLs. Hex bins were clipped to the county boundary.

5899 total hexes within the 6 counties, 2395 hexes (Hex_EFU_Large) that intersect with EFU zone boundary or contain a use/dwelling point.

Hex area is roughly 1 square mile, which is larger than the median area of the PLSS boundaries that contain a dwelling or use.

Creating SMALL hex bins for aggregating the points and TLs. Hex bins were clipped to the county boundary.

11848 total hexes within the 6 counties, 4518 hexes (Hex_EFU_Small) that intersect with EFU zone boundary or contain a use/dwelling point.

Hex area is roughly $\mathbf{1 / 2}$ square mile, which is smaller than the median area of the PLSS boundaries that contain a dwelling or use.

\section{Aggregating information to hex bins.}


Individual hexes contain information regarding count of permits by (1) category (use or dwelling), recode, and reliability; (2) count of taxlots containing a permit by category and total/non-farm; (3) count of taxlot centroids that are contained within each hex.

(2) and (3) were used to calculate LQ tests to find clusters of activity.

Spatially Join Total_Final_Selection to hex bins to return the HexID that each point falls within.

Export table into Hex_Queries_*, to summarize the data by hex.

Determine clusters of non-farm use activity and dwellings. (1) Location Quotient to determine the relative concentration of activity for each hex in comparison to entire EFU area (2) LISA test to determine if these concentrations are spatially dependent. Combined, these tests will highlight the relative concentration of non-farm activity (LQ) and where these concentrations are spatially clustered (LISA).

STUDY AREA: Hex_EFU_Final_Medium, 2897 total hexes. Hex selection based on (1) intersection with the EFU zone raster (2) contain a non-farm permit (point) (3) removing hexes within UGBs that did not contain a point.

Calculate LQ using formula below

$$
\mathrm{LQ}=\frac{\frac{\text { \# Taxlots that contain a Permit within hex }}{\text { \# Total taxlots within hex }}}{\frac{\text { Taxlots that contain a permt within EFU Hex Area }}{\text { Total Taxlots within EFU Hex Area }}}
$$

$\mathrm{LQ}<1$ indicates that non-farm activity is less concentrated in a particular hex relative to the crude concentration of the study area.

LQ > 1 indicates that non-farm activity is more concentrated in a particular hex relative to the crude concentration of the study area.

Global Morans I to determine clustering. Measurement of covariance between a particular area (hex) and its "neighbors.” For this study, neighbors are defined as sharing a border with a hex. Generally, a hex will have 6 neighbors. A significantly spatially dependent area indicates the patterns of covariance amongst neighbors is beyond what I would expect to occur through random chance.

$$
\frac{\mathrm{N} \sum_{\mathrm{i}=1}^{\mathrm{n}} \sum_{\mathrm{j}=1}^{\mathrm{n}} \mathrm{W}_{\mathrm{ij}}\left(\mathrm{X}_{\mathrm{i}}-\overline{\mathrm{X}}\right)\left(\mathrm{X}_{\mathrm{j}}-\overline{\mathrm{X}}\right)}{\left(\sum_{\mathrm{i}=1}^{\mathrm{n}} \sum_{\mathrm{j}=1}^{\mathrm{n}} \mathrm{W}_{\mathrm{ij}}\right) \sum_{\mathrm{i}=1}^{\mathrm{n}}\left(\mathrm{X}_{\mathrm{i}}-\overline{\mathrm{X}}\right)^{2}}
$$

Anselin Local Morans I: Local Indicators of Spatial Correlation (LISA) identifies where these significant clusters occur. For this analysis, I am interested in areas that 
significantly, positively covary with one another (High-High). A High-High covariance indicates that the location quotient coefficients for an area and its surrounding neighbors are greater than the LQ mean of the study area.

LISA_Non-farmAll_Queens: 68 hexes with High-high Significance

LISA_Non-farmDwelling_Queens: 59 hexes with High-High Significance, 1204 hexes with a point

LISA_Non-farmUse_Queens 51 hexes with High-High Significance, 415 hexes with a point

\section{Selecting Clusters $\underline{(95 \& 90 \mathrm{CI})}$ based on the LQ-LISA analyses.}

Select hexes that intersect with significant (95CI) High-High areas to include neighbors and account for edge effects.

Hex_All_Selection: 264 hexes of 2897 (9\%)

Hex_Dwelling_Selection: 216 hexes out of 2897 (7\%)

Hex_Use_Selection: 205 hexes out of 2897 (7\%)

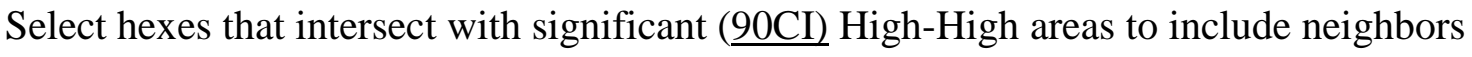
and account for edge effects

Hex_All_Selection_90CI_Combined: 312 hexes out of 2897 (11\%)

Hex_Dwelling_Selection_90CI_Combined: 254 hexes out of 2897 (9\%)

Hex_Use_Selection_90CI_Combined: 245 hexes out of 2897 (8\%)

Select non-farm dwelling and use cases that fall within their respective area clusters.

Sensitivity test to measure how much clustering is impacted by different bin sizes. LQ tests for non-farm dwellings and uses at the small (.5 mile), medium (.75 mile), and large (1 mile) hexes produced similar distributions.

LQ patterns did not vary much based on bin size. Clustering did not vary between the small and medium bin sizes, but did for the medium and large bins.

Non-farm Use Global Morans I coefficient: .038 (medium) vs .078 (large)

Non-farm Dwelling Global Morans I coefficient: .071(medium) vs .165 (large)

LISA revealed the general location of High-High clusters did not vary between the Large and Medium bins. 